Article

\title{
Smart Production Planning and Control: Concept, Use-Cases and Sustainability Implications
}

\author{
Olumide Emmanuel Oluyisola *(1), Fabio Sgarbossa 1 and Jan Ola Strandhagen \\ Department of Mechanical and Industrial Engineering, Norwegian University of Science and Technology, \\ 7491 Trondheim, Norway; fabio.sgarbossa@ntnu.no (F.S.); ola.strandhagen@ntnu.no (J.O.S.) \\ * Correspondence: olumide.e.oluyisola@ntnu.no; Tel.: +47-471-676-86
}

Received: 10 April 2020; Accepted: 5 May 2020; Published: 7 May 2020

\begin{abstract}
Many companies are struggling to manage their production systems due to increasing market uncertainty. While emerging 'smart' technologies such as the internet of things, machine learning, and cloud computing have been touted as having the potential to transform production management, the realities of their adoption and use have been much more challenging than anticipated. In this paper, we explore these challenges and present a conceptual model, a use-case matrix and a product-process framework for a smart production planning and control (smart PPC) system and illustrate the use of these artefacts through four case companies. The presented model adopts an incremental approach that companies with limited resources could employ in improving their PPC process in the context of industry 4.0 and sustainability. The results reveal that while make-to-order companies are more likely to derive greater benefits from a smart product strategy, make-to-stock companies are more likely to derive the most benefit from pursuing a smart process strategy, and consequently a smart PPC solution.
\end{abstract}

Keywords: production planning and control; smart manufacturing; internet of things; machine learning; industry 4.0; case study

\section{Introduction}

"Is pollution profitable?", asked Bragdon and Marlin [1] five decades ago as the sustainability question became a forefront topic for manufacturing managers and business management researchers. Ever since, it has become popular for companies to list sustainability goals as an integral part of their mission, even though, many fail to take tangible, significant steps to improve sustainability in operations-a practice called 'green-washing' [2]. However, since the turn of the twentieth century, there has been growing interest among managers and researchers in having sustainability as a source of competitive advantage while simultaneously addressing the growing market pressure from global consumers and supply chain (SC) partners [3,4]. This pressure, it is argued, has led towards the more holistic triple bottom-line performance measurement for manufacturing and supply chain operations management as well as the emergence of sustainable manufacturing paradigms such as the circular economy, lean and green operations, and eco-logistics [4]. In order to address this challenge, every element of manufacturing must be involved, most importantly, those elements tasked with managing all the others - that is, production planning control (PPC).

The goal of PPC is to produce what the market demands at the expected quality, volumes, time, at minimum costs, on an ongoing basis as well as to be able to adjust to disruptions to the system when necessary. The PPC system includes all the tools and processes that are required to work towards achieving that goal [5]. PPC is a critical function for manufacturing managers. One of the key elements in operations management research is the fit of the PPC system to the production system, as the level of fit often decides the efficiency, profitability and long-term viability of a production enterprise. However, 
in practice today, PPC managers must deal with several challenges such as changing regulatory policies, climate change and other global phenomena all of which appear to put the world in a state of near-perpetual turbulence. In order to deal with the increased complexity and new market demands, production managers continually attempt to improve product and process flexibility, thereby leading to increasing depth of bill-of-materials and greater variation in production routings [6]. This causes PPC to be more challenging and the consequence is that a significant proportion of production lead time is still wasted as queueing or waiting time [7].

Furthermore, recent developments in information and communications technology (ICT) paradigms-within the concept of industry 4.0-indicate the potential of transforming all stages in the lifecycle of products (from design, sourcing, manufacturing, to distribution, consumption, and recycling) by enabling real-time planning and control of the factory and supply chain operations and thereby minimizing waste [8-10]. While several conceptual studies on smart manufacturing have been published, mainly focusing on manufacturing systems configuration and features, very few empirical in-depth case studies have been reported in the literature that specifically focus on the management processes of such systems [11,12]. Additionally, only a few of these studies address the importance of production planning and control in achieving the vision of smart manufacturing $[11,13,14]$. We think that this is a missed opportunity, as the PPC process is analogous to a brain for the production system and is the most critical "smartness" element of a smart factory. Furthermore, addressing the subject from the perspective of PPC enables firms to gradually advance in a holistic manner towards smart and sustainable manufacturing.

Consequently, this study addresses how a 'smarter' or machine-intelligent PPC system (hereafter, smart PPC) can be achieved in practice, and the sustainability implications of such a system and its processes. Smart PPC combines emerging technologies and capabilities in the industry 4.0 framework with PPC processes in order to improve the performance of the production system through real-time, data-driven, and continuous learning from a more diverse range of data sources than usual. The following is a non-exhaustive list of possible goals for smart PPC: to use real-time demand and production system data, i.e., reduce uncertainty from forecasts; to be dynamic, thus updating frequently, and reactive to real-time data; to use an expanded set of factors and data including telemetry data; to be able to accurately predict short-term requirements and support increased flexibility; and to capture and use the experience of the operators in the production system. If these goals can be achieved, it will lead to more precise planning processes, a reduction or elimination of various sources of waste, and ultimately to a competitive advantage. Thus, this paper seeks to answer the following research questions (RQs):

RQ1: What are the elements of a smart PPC system?

RQ2: What are the constraints, enablers and use-cases of smart PPC in practice?

RQ3: What are the implications of smart PPC for sustainable manufacturing?

In order to answer these questions, we present a concept for such a smart PPC system, adopting an incremental approach. While we will attempt to illustrate a typical architecture of such a system, the software architecture details are not the focus of this paper. Rather, through RQ1, we address components-inputs, processes and outputs—of the system and assume the generic service-oriented architecture. This approach is the basis for many notable architectures for emerging industry 4.0 applications [15]. RQ2 is ever more pertinent now as the dust settles on the industry 4.0 wave and results about successes and failures in early implementations begin to trickle into the public domain. The latter is an important gap in this relatively young research field, as there is limited know-how of the strategic implementation of industry $4.0[16,17]$. Thus, this study lays the foundation for an approach towards industry 4.0 through smart PPC.

The remainder of the paper is structured as follows: we present the theoretical background to the conceptual model in Section 2. We describe the underlying framework guiding the concept development, together with the case selection, data collection and analysis processes in Section 3. 
Thereafter, we present the developed framework and conceptual model in Section 4. We illustrate this model using the cases in Section 5. We follow this with a thematic discussion in Section 6. We then wrap-up with the conclusions, research limitations and future research topics in Section 7.

\section{Theoretical Background}

The literature is replete with studies investigating disparate elements of PPC and elements of industry 4.0. However, there is much insight to be gained from a holistic view of PPC and industry 4.0 for smart PPC to be realizable, and consequently, the vision of smart and sustainable manufacturing. Therefore, this section revisits the theory on hierarchical PPC systems, its processes and challenges and industry 4.0 as a foundation for smart PPC. The section concludes with a literature on constrains, enablers and an attempt to present a theory-the structural contingency theory-to explain the smart PPC concept and its application in the selected cases.

\subsection{The PPC System and Processes}

PPC is often described using hierarchical frameworks which presents the various elements of the PPC process at varying levels of detail and time horizon. This hierarchy supports the 'drilling down' approach that business managers seek when making decisions regarding their production systems. One notable PPC framework, created by Vollmann et al. [6], is the basis for most traditional planning systems in production today. The framework describes the strategic (long-term), tactical (medium-term) and operational (short-term) stages as the common levels of planning that exists within a typical enterprise resource planning (ERP) system regardless of the type of industry in question. While this framework has faced some criticism for not capturing the several feedback loops that are witnessed in real life production systems, it remains popular due to its comprehensiveness and its built-in optimization capabilities [18].

Nevertheless, several others PPC frameworks also exist, for example Bonney [19], which present a slightly different take on the PPC process and highlight the importance of feedback loops. Notably, these loops are more frequent and important in the tactical and operational stages of PPC. Moreover, regardless of whether the system in question is built on a hierarchical framework, PPC systems have become colossal, difficult to implement and maintain, and unwieldy to adapt to the needs of today's production environment [18]. Taking these loops into consideration, we adapt the three-domains framework into a holistic PPC framework, as depicted in Figure 1.

The strategic level adopts a long-term, aggregated view of manufacturing operations. The process begins with sales and operations planning (S\&OP) which aims to balance overall demand with the available capacity. S\&OP receives demand data (volumes per product family per planning period) and in some cases meta data (such as forecast uncertainty) as input from demand management (DM) and future available aggregate capacity as input from resource planning (RP). Thereafter, the aggregated plan generated at this level is disaggregated from the product family into individual products. Since the plan is aggregated and with a relatively larger time horizon than others, it is not often accurate. The relevant data for this stage typically includes demand forecast data which can be computed from historical demand data or estimated from experience by the sales and marketing team or a combination of the two [6]. The primary output is the master production scheduling (MPS), which encompasses the purchasing and production plans at an individual product level by time period, typically weeks. The output of this level is the input to the tactical level.

At the tactical level, the MPS records are combined with bill of materials data and inventory data in order to calculate the components' and parts' requirements, and make recommendations to release replenishment orders for materials, a process called materials requirements planning (MRP). Based on the production system's capabilities and lead times which dictates the capacity requirements planning (CRP) process, it is possible to release detailed material and capacity plans with shorter time horizon (typically weekly). These plans are revised frequently, and the output of this stage is production plans and replenishment orders for materials, which in turn is the input for the operational stage. 


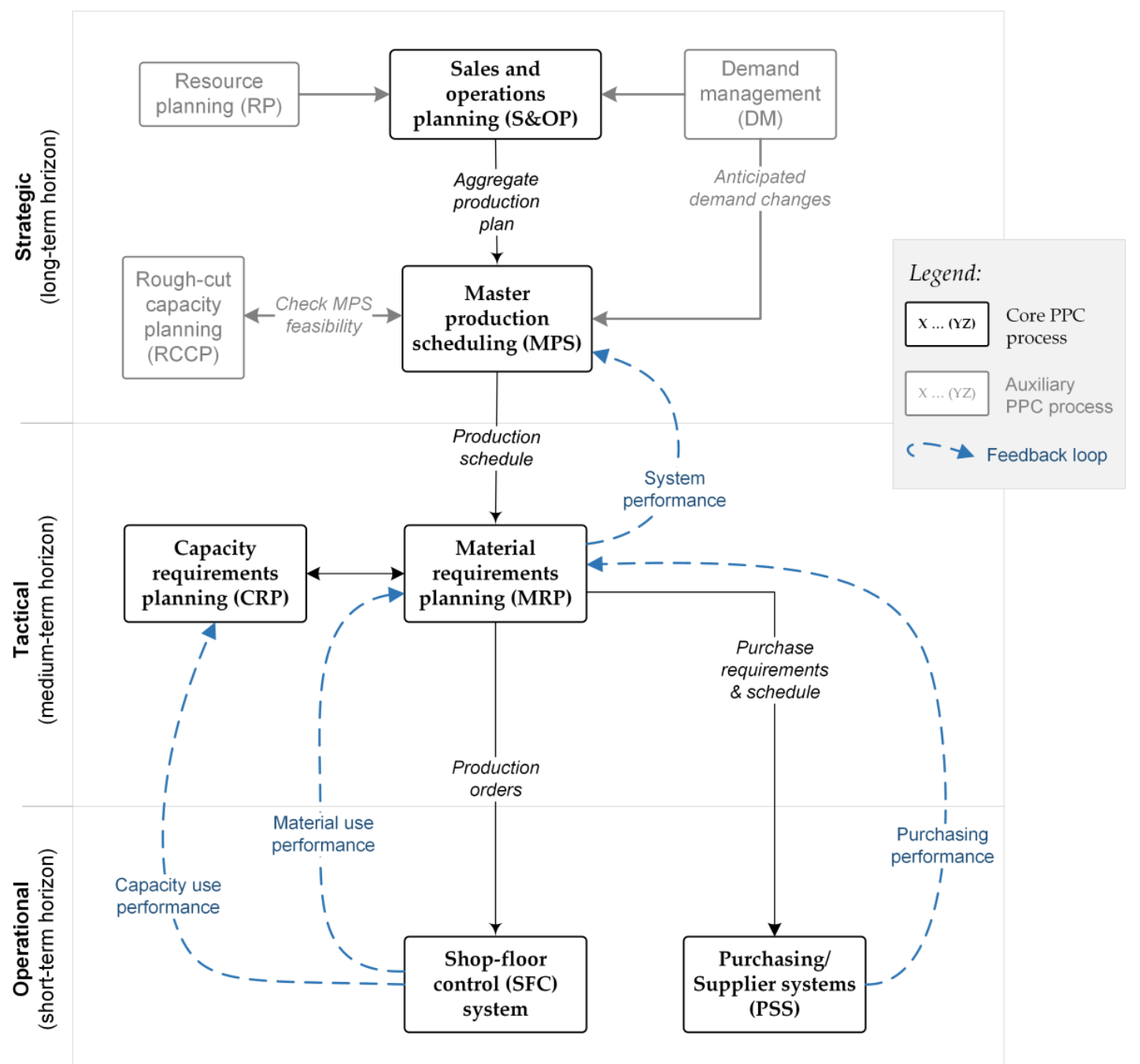

Figure 1. The production planning control (PPC) system levels and processes (adapted from $[6,19,20]$ ).

Finally, at the operational level, the concern is about how to execute the production order using the materials and capacity plans from the MRP and CRP. The processes entail day-by-day, shift-by-shift detailed scheduling, the coordination of the actual manufacturing processes (shop floor control, SFC), and the issuance of purchasing schedules to the purchasing function or supplier systems (PSS) for the supply of materials required to execute daily operations $[6,19]$. The documents at this level are purchase orders at the component level and work orders and job lists at work centres. This stage also involves the control, measurement, and evaluation of the performance of the production operations and suppliers.

\subsection{PPC Challenges}

One key limitation of PPC at the strategic level is that it implicitly assumes that the effect of extraneous factors such as weather or industrial policy changes, global economic downturns and other disruptions average out from year to year. This often leads to the use - by planners and operators-of excessive capacity, buffers and safety stock in the production system. Furthermore, since the data is aggregated, the quality often varies depending on how data-driven the company is. Challenges include quality of data in the long term (as the business environment continues to change), frequency of update, etc. In this case, having real-time data does not necessarily lead to any advantage provided the data is accurate. Perhaps more important is the span of the data, in which case "longer is better" in order to enable various simulation scenarios. Finally, managers of production systems often must 
make resource planning and flexibility related investment decisions based mainly on uncertain forecast data [6]. Therefore, the S\&OP process must overcome variations in historical demand, uncertainties in demand forecasts, and unavailability of demand data. Similarly, the MPS process must deal with issues related to data integrity and completeness, estimation of product-level demand, inventory variability leading to difficulty in estimating available-to-promise, rescheduling frequency periodic scheduling while events alter production system, and a lack of feedback on the accuracy of resource planning.

At the tactical level, the challenges of traditional PPC include planning complexity due to data integrity concerns, product mix exacerbated by increasing product customization needs, estimation of production volumes, control principles that minimizes work-in-process inventory, etc. [6]. Thus, the MRP process must deal with issues regarding the updatedness of bill-of-materials with respect to (w.r.t.) components and levels; inventory data accuracy-what is produced and exact storage location; and lot-size determination and revision policy. The CRP process must handle the updatedness of process routes/charts and recipes; accuracy and integrity of production instructions; process variability; variability in resources capabilities and capacity; and continually monitor the size of buffers [20]. Production managers deal with all these challenges using levelling and lot-sizing techniques within the constraints of the planning solution that the company employs. They must also deal with the limitation that the production planning process is run periodically while the demand situation is continuously changing. They must also manage the contrast between the objectives of long-term planning versus short-term scheduling - that is, levelling versus the minimization of earliness and tardiness and nonexecution [21].

As shown earlier, at the operational (short-term) level, the status of the production system is changing in real-time and the agility and precision of the PPC system in adapting to the changing production environment is critical. However, the reality in most factories is that it is challenging to track and accurately predict work-in-process inventory and resource status, and the system is continuously being disrupted by rush-jobs and unplanned machine breakdowns or large changeover and set-up times $[9,22]$. Specifically, the PO process is challenged by the reliability of supplier quality and timeliness accuracy [23]. Furthermore, SFC processes and systems handle collection of operations data in real-time, job tracking on the shop-floor, resource performance tracking, and estimating and updating production schedule after rush jobs. Yet, a significant proportion of production lead time continues to be wasted in the form of queueing or waiting time [7]. Moreover, the manufacturing technologies are increasingly becoming sophisticated, and the SFC systems are required to handle a disparate set of data types and sources.

Overall, a few underlying challenges commonly affect the strategic, tactical and operational levels of the PPC system. Promotions and campaigns which are becoming commonplace can significantly disrupt supply chains. In addition, the quality and completeness (w.r.t. the span of breadth) of data and information used is a common challenge affecting resource efficiency and demand fulfilment [24]. These become even more important as systems become increasingly computerized and automated.

\subsection{Towards Smart PPC in the Era of Industry 4.0}

The temporal proximity or 'real-time' needs of PPC is a major uphill climb for conventional enterprise systems such as the ERP, manufacturing execution system (MES), or advanced planning and scheduling (APS) systems. Moreover, another critical limitation of these systems is that deviations are common between information in these enterprise systems and the reality on the shop floor and across the supply chain [25]. Furthermore, these enterprise systems are commonly configured to collect data from a narrow range of sources in the production system typically from production lines and perhaps warehouse inventories. However, in many production systems and value chains, several more factors influence performance. For example, in the food and beverages industry, the weather affects not only the production but also the distribution and consumption rates of numerous products. Being able to capture and use data from a broad range of sources presents an opportunity for better PPC performance in the current era. These limitations can be addressed by Industry 4.0. 
Industry 4.0 envisages a state of manufacturing in which the product's end-to-end lifecycle stages are integrated, the manufacturing systems and internal functional units are networked (vertical integration), and the external value creation network is integrated (horizontal integration) [12,26,27]. This vision is enabled by the recent advances in technologies, including cyber-physical systems, internet of things (IoT), big data analytics (BDA), machine learning (ML), augmented reality, cloud and edge computing, and additive manufacturing [12,28]. Therefore, with all things connected, data generated from these integrated systems with the plant and across the value chain will enable real-time control (and, consequently, dynamic re-planning and rescheduling) of the factory and supply chain [8,9]. IoT, BDA and ML connected to and run via the cloud can address these temporal proximity needs of a smart and sustainable production value chain [29]. This specific collection of emerging technologies is at the cutting edge in the development of information systems (IS), having seen tremendous investments in research and development in the previous decade partially due to the significant reduction in the costs of computation power and data storage [29]. The cost reductions have been possible due to the reducing cost of hardware and the economies-of-scale achieved in cloud computing [17].

Furthermore, a key tenet of industry 4.0 is that manufacturing systems will be sentient and autonomous [29]. This will enable the development of real-time planning and control of the plant and supply chain operations thereby minimizing wastes in the system as every product will be produced as close as possible to when it is required by a customer [9]. In addition, the ability of BDA and ML tools and technologies to manage data with ordinarily challenging diversity (or variety) is an opportunity. Since computerization of the planning process is, by itself, not new, and enterprise systems and spreadsheet solutions have been used for decades, many production managers find it challenging to step into this new way of using data and ICT [30].

In addition, digital technologies have the potential to improve social and environmental sustainability when developed into organizational capabilities [16]. In a recent study, Dubey, et al. [31] found that BDA improves sustainability performance among Indian firms, consistent with previous studies. However, they also found that the primary driver for its adoption was its expected economic impact rather than any social or environmental benefit. This latter point further highlights previous findings which reveal how economics drives most transformational efforts including those publicized as sustainability programmes [2]. Meanwhile in another similar survey-based study in Brazil, Dalenogare, et al. [32] found that the maturity of certain digitalization technologies within the local context can lead to different expectations in their contributions to operational and sustainability performance. In their study, they found a strong positive correlation between the use of sensor technologies and the resulting big data with operational performance (agreeing with [31]) but failed to find a significant relationship between industry 4.0 and sustainability. They also found, contrary to popular belief, that not all technologies are expected to lead to operational performance improvements.

However, more recently, studies are beginning to indicate that numerous companies are struggling in their efforts to become more data-driven and attain smart operations [17]. The realities of the adoption and use of BDA, ML, cloud computing, and related smart technologies have been much more challenging than anticipated. From anecdotal evidence with industry partners, and as the extant literature shows, certain projects are likely to succeed while others are more likely to fail depending on the structure of the supply chain, the characteristics of the production system, and the products attributes. In other words, there is the question of contextual 'fit' with the planning environment factors in terms of whether a company that applies these technologies in manufacturing operations will succeed or fail $[16,33]$. Therefore, the selection and implementation of smart technologies towards a smart PPC system requires some consideration for the constraints of each technology and the characteristics of the production system.

\subsection{Constraints, Enablers and the Structural Contingency Theory}

From the above discussion, it is therefore evident that it is not sufficient for a manufacturing firm to select a technology and apply it and expect great results without due consideration for the 
intra- and inter-organizational factors that play a role in this regard [34]. Intraorganizational factors are those that define the working principles and the control of processes within an organization. Examples of such factors include the production process, products attributes, and human resource management systems. Interorganizational factors, such as the pressures from supply chain partners and the intensity of competition in an industry, can constrain or enable a company's adoption of industry 4.0 technologies for PPC to enable a better synchronization of planning efforts within the supply chain $[35,36]$. While these factors can be expected to play a role in the fit of industry 4.0 technologies with the production system, the extent and the nature of this influence is unknown.

In a related study focused on the extended enterprise view, Ngai, et al. [37] identified cultural issues, functionality requirements and legacy IT infrastructure, organizational and people-related challenges, technical support and training of relevant personnel as the critical success factors for successful ERP implementations [37]. Koh, et al. [38] extended these ideas and identified barriers, drivers, and critical success factors for enterprise-wide ERP (ERPII) implementation across supply chains. They observed that while vendors and suppliers tout real-time information, better decision-making power, and efficiencies in operations as the key drivers for ERPII implementation, users and customers are more concerned with how ERPII can provide new simpler and shorter ways for value creation, core competency integration, customer demand responsiveness, and improved product innovation or customization. They further identified barriers such as organizational inertia, resistance to change by employees, cost, gap between the theory and practice of the extended enterprise, disparate data standards and data inaccuracy as important factors. In addition, organizational structure and the learning culture have also been identified as critical factors [34].

More recently, de Sousa Jabbour, et al. [39] extended the concepts related to critical success factors into research on how industry 4.0 can enhance environmental sustainability in manufacturing. They selected 11 nontechnical factors including management leadership, strategic alignment, training and capacity building, empowerment to be innovative and discover new uses, national and regional differences, and organizational culture. However, the presence of other studies with conflicting results indicates that the influence of organization culture on the sustainability performance of firms implementing digitalization and industry 4.0 remains unclear [31]. Arguably, the influence of these internal and external factors varies based on the context that each production manager must consider when planning their manufacturing operations. Considering all these factors, the production enterprise is only likely to achieve the expected performance benefits of industry 4.0 if the technologies are configured and implemented in a manner that fits with the characteristics of its production system. Furthermore, certain industries (such as the engineering and equipment manufacturing industries) expect a long-term strategic benefit and are willing to pursue industry 4.0 regardless of possible challenges or implementation risks [33].

An appropriate foundational theory for addressing these kind of research problems is the structural contingency theory, which argues that organizational processes must align with the organization's environment [40]. As an example, Hicks, et al. [41] applied the structural contingency theory to explain the characterization of different engineer-to-order (ETO) archetypes in accordance with how ETO companies reorganize their internal and external supply chains to remain competitive in the face of changes in their production environments. Thus, it can be argued that the use of technologies in production systems ought to fit with the characteristics of the system. While sensor technologies have a wide application domain for example, in order to derive value from these sensors, several contextual factors must be considered. Often, what works in one industry will lead to poor results in another, like in the case of RFID application in the control of plastic pipes manufacturing [22,42]. Similarly, the structural contingency theory can also be used to explain for the influence of the supply chain and industry context $[40,41]$. 


\section{Methodology}

Following a description of the PPC system, its processes, and current challenges, and after developing a case for smart PPC and highlighting the constraints and enablers of such a system from the applicable industry 4.0 and PPC theory, we proceed to develop a conceptual model of smart PPC and case data to illustrate its use. Case research is fitting for research on subjects where there is a need to capture details and the nuances of complex phenomena like in the case of a PPC system being transformed by new advanced technologies [43]. Since one of the purpose of study is to identify and describe key/salient variables (i.e., constraints and enablers) and draw maps (or scope) of these variables for smart PPC, the research design will benefit from using a few, in-depth case studies with data collection by way of observations, interviews, historical reports and survey questionnaires [44].

\subsection{Conceptual Model Development}

After collating and analysing the problem with current PPC systems, and considering alternatives for improving their performance, we chose (among the alternatives) to investigate the potential of emerging industry 4.0 (I4.0) technologies. Due to our interests in resource-constrained manufacturers, we chose to build our concept on an incremental model which enables gradual advancements towards a desired state. We chose the model by Schuh et al. [34] which presents an incremental view of the stages of evolution towards the goal of an agile manufacturing company-that is, be able to respond accurately (using data rather than mostly managerial intuition), quickly (almost in real-time) and continuously (rather than at set, often long periodic intervals). They also highlighted how the model was developed from empirical data, with case studies, and the benefit for small and medium enterprises (SMEs) who have limited financial capacity and risk appetite towards seeming adventurous industry 4.0 projects. This previous point is particularly relevant because even though the reduction in computation costs is enabling digitalization and industry 4.0, small and medium-sized manufacturing companies which employ a large part of the global population are the ones that are more likely to be disrupted by the ongoing market transformation [12].

\subsection{Data Collection and Analysis}

The use of empirical data is important in this research area because the object of study is new and evolving [44]. Furthermore, there is great scientific and managerial benefit to document the actual experience of companies attempting to make advancements in the subject of this study. The cases selected for this study are members of a large industrial research network, and have made had a sizeable, publicized digitalization effort within the past three years. Two are semi-process manufacturing companies and the other two are discrete manufacturing companies. An overview of cases and interviewees is presented in Table 1 . We began by analysing potential cases using available data from secondary sources and published reports about the case companies, their market situation, and each company's competitive environment. This was to ensure that each company to be included in the study met the requirements that they operated within a supply chain (SC) experiencing some changes due to digitalization and that they will be willing to participate in this study by sharing insights regarding their efforts as it relates to our research questions. From this pool, four companies were eventually selected.

An interview protocol was developed to highlight the data required to address our research questions and preliminarily administered in company A. The sections in the protocol followed the classification of PPC environment factors described in Jonsson and Mattsson [45]—namely, markets (covering the demand and supply factors), product attributes and process characteristics. This was then followed by a description of the PPC system, process, and challenges; finally, digitalization initiatives and sustainability considerations were then discussed. After the first interview, the protocol was updated to address the gaps in the framing of the research questions, thereby eliminating ambiguity and ensuring consistency at the point of subsequent interviews. The revised protocol (Appendix A) 
was then administered with respondents from company A and thereafter administered in the other case companies B, C and D. In order to reduce social desirability bias, we assured interviewees that the collected data will be anonymized if and when it is to be used in publications, similar to Wilhelm, et al. [46]. After collecting case data through interviews, we proceeded to transcribe the interview data while ensuring sufficient detail and structure for a thematic analysis and discussion [47].

Table 1. Overview of cases and interviews (real names of companies anonymized).

\begin{tabular}{clcccc}
\hline Case & Category Description & $\begin{array}{c}\text { Total no. of } \\
\text { Industry 4.0 (I4.0) } \\
\text { Projects }\end{array}$ & $\begin{array}{c}\text { No. of I4.0 Projects } \\
\text { Affecting PPC }\end{array}$ & $\begin{array}{c}\text { No. of Projects } \\
\text { with SC Partners }\end{array}$ & $\begin{array}{c}\text { No. of } \\
\text { Meetings }\end{array}$ \\
\hline Company A & Confectionery products & $>3$ & 2 & 1 & $\begin{array}{l}\text { Production planners } \\
\text { SC director } \\
\text { SC manager } \\
\text { Technical projects } \\
\text { engineer } \\
\text { Innovation manager }\end{array}$ \\
Company B & $\begin{array}{l}\text { PVC pipes \& drainage } \\
\text { subsystems }\end{array}$ & $>5$ & 2 & 1 & $\begin{array}{l}\text { Master planner } \\
2\end{array}$ \\
Company C & $\begin{array}{l}\text { Equipment for small \& } \\
\text { large ships } \\
\text { Agricultural \& } \\
\text { industrial balers }\end{array}$ & $>3$ & 1 & - & 1 \\
2 & 1 & $\begin{array}{l}\text { Production manager } \\
\text { Innovation manager }\end{array}$ \\
\hline
\end{tabular}

\section{The Smart PPC Concept}

This section presents the developed smart PPC concept and a description of its elements- that is, addressing RQ1. As companies digitalize their manufacturing operations in the move towards industry 4.0, they progress in stages. Schuh et al. [34] identified six progressive stages that an operation on the path towards smart manufacturing should follow. These are computerization, connectivity, visibility, transparency, predictive capacity, and adaptability. To simplify, in line with industrial practices, we reclassified the six stages into three-connected, transparent, and intelligent. These three stages, depicted in Figure 2, relate easily to the managers of production systems who seek better tools to improve their ability to respond quickly and accurately to changes in the business environment. A description of the theory behind each stage, the conceptual model and a table of potential use-cases for smart PPC is provided in the subsections below.

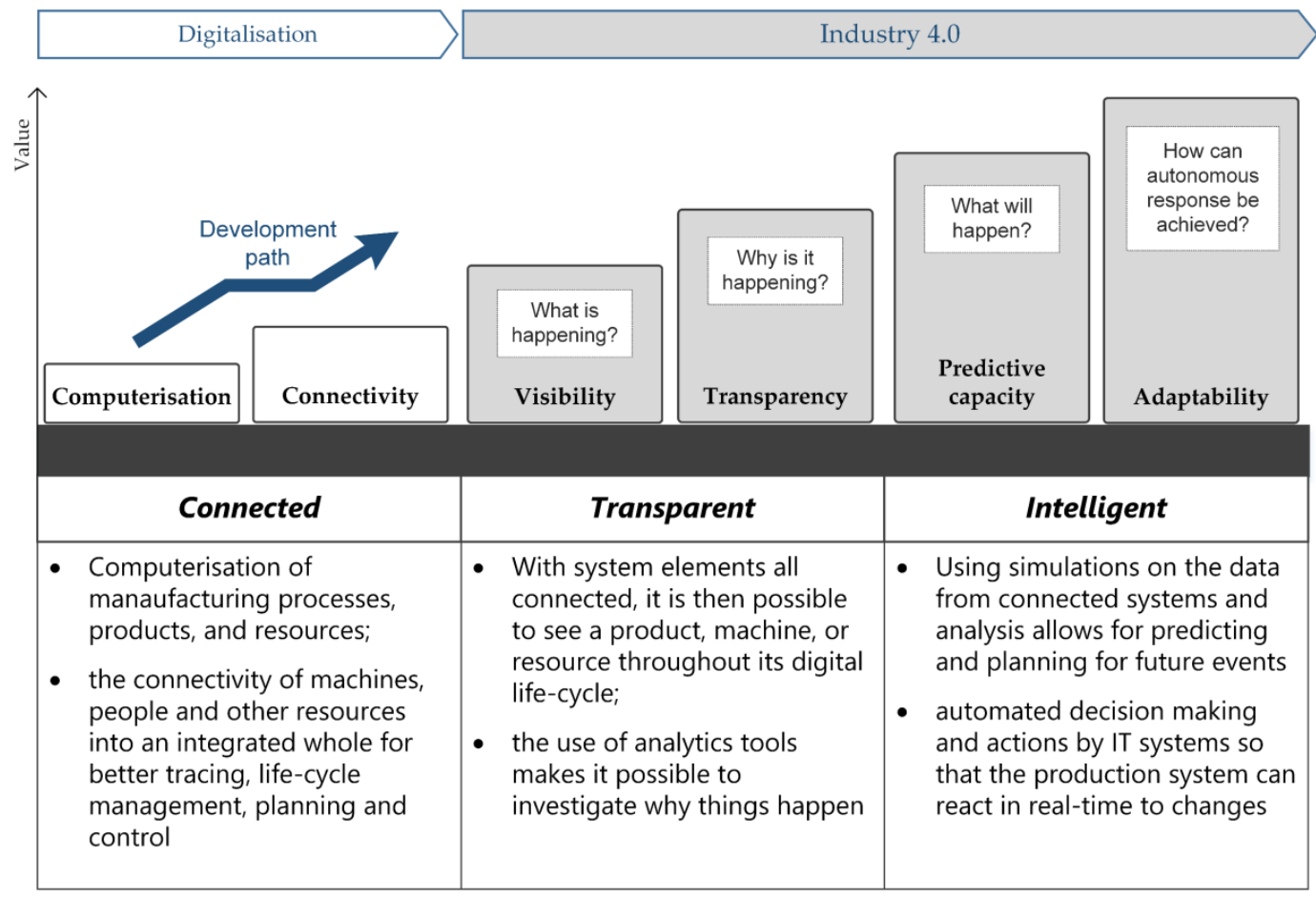

Figure 2. The path towards the development of smart production systems (adapted from Schuh et al. [34]). 


\subsection{Connected}

The computerization of PPC processes is, by itself, not new. ERP systems and spreadsheets have been used for decades and almost every production system today is planned and controlled to a certain extent by either of these technologies. Moreover, the use of spreadsheets does not appear to be waning even with the advances in ERP systems and other planning solutions, probably due to the flexibility and ease of use that spreadsheet solutions afford most production planners [48,49]. In addition, production processes nowadays tend to have more electronic components and programable logic controllers (PLC), thereby enabling greater automation of production processes. Increasing computerization implies that all elements in a production system have a digital life and can therefore be connected to a digital industrial network in the smart factory.

On the contrary, connectivity is only just becoming widespread in this decade of digitalization and industry 4.0, as sensors and networking infrastructure gradually become ubiquitous and more affordable [29]. This sensing will be achieved using auto-identification and telemetry data collection sensor technologies such as radio frequency identification (RFID) technology, beacons and IoT devices [50]. Furthermore, since the move from the internet protocol version 4 (IPv4) to the new internet protocol version 6 (IPv6) standard, which can theoretically allow up to $3.4^{*} 10 \mathrm{E} 38$ internet addresses, it is now possible to connect things that hitherto would have been too complicated or expensive to connect to the internet $[34,51]$. Therefore, with the increasing ease of connecting 'things' to networks, everything can be connected, traced, tracked, measured, and improved and all the data generated by the action or movement of things can then be used to improve the design of systems, and the planning and management of operations. Consequently, tracking and tracing items of resources within a factory and in the supply chain becomes much easier [29].

IoT sensors can, through IoT edge devices, interact with the physical production system by sending location, status, and compute requests, and by receiving data and instructions from services hosted on cloud infrastructure. IoT Edge devices are more suited when there is a need for quick reaction (e.g., action to prevent a crane from collapsing if the sensor data already detects that this might happen, or action to prevent an automated tractor from colliding with an approaching operator) particularly when there is higher-than-acceptable device-to-cloud data transfer latency, and when bandwidth could be a challenge (e.g., on offshore platforms that use satellite internet connection and have several functions that demand the available bandwidth) [52].

Consequently, real-time planning and control of the production system and supply chain becomes possible. Examples abound particularly in the retail industry, which gained popularity in the past two decades due to the performance improvement achieved in inventory management and distribution logistics $[53,54]$. The same principles are now being applied in job shops, production lines and warehouses at equipment manufacturers $[22,55]$. Thus, computerization and connection enable smart PPC by enabling the determination of the precise location of products, routes travelled in the factory, status of machines and other resources, frequency of use, idle times and nonvalue-added time, etc., all of which is information that can then be processed with data analytics solutions in order to obtain insights into the state of the system, why the system is performing in a certain manner, and the performance of the PPC processes that are employed to manage that system.

\subsection{Transparent}

When 'things' are computerized and connected, it is possible to make a digital model of not only individual machines or factories but also components and final products moving through the production processes-that is, a digital shadow of the entire system and all its elements $[34,56]$. The digital shadow represents a digital state map of the production system and accepts data from the connected elements of that system to present it in a form that is typically visual, and which production managers and planners can use to simulate and plan future states and operations of the system. Meanwhile, a digital twin goes a step further and, in addition to accepting data, can send action instructions to the production system [57]. Thereafter, the data can be collected from within the 
factory or on a truck transporting raw materials or other critical components or from the sensor-enabled pallets at customer warehouses. It then becomes possible for a production planner to analyse the data in order to determine the sources and root-causes of logistical problems at the strategic, operational and tactical levels using dashboards with real-time KPIs collected from integrated enterprise and IoT systems [34,58].

Regardless of the type used, or even in cases where no digital shadow or twin is used but that KPI data specific to the production system are sent to a database for processing and analysis, there is a tendency for this data to be enormous and of high-dimensionality if they are collected from several IoT sensors in a typical production system. This situation presents both an opportunity and a challenge. First, the abundance and breadth of data enables higher precision of simulation models of production systems [58]. However, this also creates a case in which standard data processing technologies are not capable to derive insights from such (big) data. As such, new emerging technologies and methods for big data analytics such as MapReduce and Hadoop would be required to derive value from all the data being generated [14]. Moreover, even when the data processing challenge is overcome, there is also the causality problem which requires an understanding of the underlying engineering principles and business context to translate data correctly (e.g., translating sensor measure depth in a raw material silo into estimated volume of weight of materials in the silos) and to establish cause and effect relationships from the data that is generated by the system and the production and logistics KPIs of interest [34].

Hence, when used appropriately, BDA enables the transparency of process performance, critical materials, critical paths, supplier delivery performance, process material yield, and other factors that affect the behaviour and output of the system $[9,31,36,58]$. However, this smart PPC level still requires a production planner who is highly skilled in both production planning and BDA tools to actively examine the data, process and analyse it, and make decisions. With the increasing research on and wide application of ML and artificial intelligence (AI), there is potential for a machine-intelligent, self-optimizing PPC system which can handle all the relevant processes, process all the data, and interact with planners periodically, as determined by the production managers.

\subsection{Intelligent}

An intelligent system should be able to combine data from several sources about itself and its environment in order to learn and autonomously predict events which may influence its performance with regard to predetermined goals. In production, that implies being able to predict production delays, supplier delays, reduction in demand, etc. in order to avert a performance failure. Recent industrial interests in ML have led to significant advances which make these technologies and methods more feasible now for PPC than, say, a decade ago. Research into the use of AI approaches to planning and scheduling production systems have been going on since the 1980s, although those were in the form of expert systems and knowledge-based systems [59]. However, it is the interest of companies such as Google, Facebook and Amazon with vast compute and human resources that has extended the capabilities and possible use-cases of ML and also extended neural networks (a type of ML) to new depths (i.e., deep learning) with advanced techniques and applications.

There are three types of ML—supervised, unsupervised, and reinforcement learning-and all three types have been explored in PPC research, although limited empirical case studies have been reported. Supervised and unsupervised ML techniques have been applied in planning and control for predicting supply disruptions [60,61]. Reinforcement learning has been experimented upon for real-time scheduling [62]. Other noteworthy empirical studies of ML use in PPC have also been published. Using case studies, Garetti and Taisch [20] explored the use of artificial neural networks (ANN) for the selection of a production control strategy in the context of a valve manufacturer, and as a decision support system for plant parameter definition at the paint shop of a wagon manufacturer, thereby highlighting the pros and cons of each method and the implementation challenges. Except for a few cases such as these, most of the ANN research output at that time lacked real-life application [63]. 
Furthermore, these cases have been applied to static, one-off PPC problems, while research that examines the dynamic case of real-time learning PPC system was rare.

However, in the last decade, deep learning has received enormous attention from the software industry and has witnessed significant application in industries beyond manufacturing. Prior to that, several studies were published that investigated the use of ML methods in subsets of the PPC system. For example, Hruschka [64] used the marketing variables (current and one-month lagging advertising budget, as well as the retail price), along with an exogenous variable (average monthly temperature) to predict sales for an Austrian consumer brand. However, the author highlighted how computer processing power was a challenge due to the low learning speeds of ANN at that time.

In current production environments, an autonomous solution can be built using robotic process automation (RPA) with event-driven or scheduled applications and data pipelines for a connected system of applications. According to Wróblewska, et al. [65], RPA can facilitate an iterative upgrading of solution modules and therefore enables continuous learning. Thus, smart systems can be pre-programmed so that they not only run independently but also learn and improve without human intervention. Nevertheless, the case study in [65] (as with most cases in the RPA literature) was within financial services and document management. Despite the potential benefits, we find that there is currently little application in production management, and more so in PPC.

\subsection{Conceptual Model and Matrix of Use-Cases for Smart PPC}

The eventual conceptual model of such a smart PPC system is illustrated in Figure 3.

The smart PPC system incorporates the different levels of the PPC domains and intelligently manages all the key processes using data from diverse sources and allows human intervention. It should also provide a mechanism for continuous feedback from the production system to handle events that occur, in the same manner that a human-managed PPC system would work. Furthermore, when viewed in terms of PPC challenges, several use-cases can be identified (from the literature) for each of the three stages that leads to a smart-PPC system, as depicted in Table 2.

Table 2. A matrix of use-cases for an incremental adoption of smart PPC.

\begin{tabular}{|c|c|c|c|}
\hline Challenges in PPC levels & $\begin{array}{l}\text { Connected Use-cases } \\
\text { (with IoT-Internet of } \\
\text { Things) }\end{array}$ & $\begin{array}{l}\text { Transparent Use-cases (with } \\
\text { BDA-Big Data Analysis) }\end{array}$ & $\begin{array}{l}\text { Intelligent Use-cases (with } \\
\text { ML_-Machine Learning) }\end{array}$ \\
\hline \multicolumn{4}{|l|}{ Strategic } \\
\hline $\begin{array}{l}\text { Sales and operations planning (SEOP): } \\
\text { 1. Variability in historical demand } \\
\text { 2. Uncertainty in forecast demand } \\
\text { 3. Unavailability in demand data } \\
\text { 4. Investment assessment for green and } \\
\text { brown field resource capacity } \\
\text { Master production scheduling (MPS): } \\
\text { 1. Data integrity and completeness } \\
\text { 2. Estimation of product-level demand } \\
\text { 3. Inventory variability leading to difficulty } \\
\text { in estimating available-to-promise } \\
\text { 4. Rescheduling frequency is periodic, while } \\
\text { change events are continuous } \\
\text { 5. Feedback on accuracy of resource planning }\end{array}$ & $\begin{array}{c}\text { Real-time point-of-sale } \\
\text { data } \\
\text { Real-time } \\
\text { goods-in-transit data }\end{array}$ & $\begin{array}{l}\text { Demand summary } \\
\text { Visibility in production } \\
\text { resource performance patterns }\end{array}$ & $\begin{array}{l}\text { Continuous lot-size optimization } \\
\text { Multi-sourcing of data with } \\
\text { error-detection mechanisms } \\
\text { Multi-horizon scheduling and } \\
\text { planning with KPIs }\end{array}$ \\
\hline \multicolumn{4}{|l|}{ Tactical } \\
\hline $\begin{array}{l}\text { Materials requirements planning (MRP): } \\
\text { 1. Data integrity } \\
\text { 2. Bill-of-materials updatedness w.r.t. } \\
\text { components and levels } \\
\text { 3. Inventory data accuracy - what is } \\
\text { produced and exact storage location } \\
\text { 4. Lot-size determination and revision } \\
\text { Capacity requirements planning (CRP): } \\
\text { 1. Process routes/charts updatedness w.r.t. } \\
\text { updates to processes and recipes } \\
\text { 2. Data accuracy and integrity } \\
\text { 3. Process variability } \\
\text { 4. Variability in the capabilities and capacity } \\
\text { of resources }\end{array}$ & $\begin{array}{l}\text { Capturing the behaviour } \\
\text { of production assets }\end{array}$ & $\begin{array}{l}\text { Enables robust lifecycle } \\
\text { assessment of assets and } \\
\text { precise capacity planning }\end{array}$ & $\begin{array}{l}\text { Continuous lot-size optimization } \\
\text { Intelligent planning of inventory } \\
\text { control policy }\end{array}$ \\
\hline
\end{tabular}


Table 2. Cont.

\begin{tabular}{|c|c|c|c|}
\hline Challenges in PPC levels & $\begin{array}{l}\text { Connected Use-cases } \\
\text { (with IoT-Internet of } \\
\text { Things) }\end{array}$ & $\begin{array}{l}\text { Transparent Use-cases (with } \\
\text { BDA-Big Data Analysis) }\end{array}$ & $\begin{array}{l}\text { Intelligent Use-cases (with } \\
\text { ML-Machine Learning) }\end{array}$ \\
\hline \multicolumn{4}{|l|}{ Operational } \\
\hline $\begin{array}{l}\text { Purchasing function or supplier systems } \\
\text { (PSS): } \\
\text { 1. Reliability of supplier quality } \\
\text { 2. Supplier quantity and timeliness accuracy } \\
\text { Shop floor control (SFC): }\end{array}$ & $\begin{array}{l}\text { Traceability of supplied } \\
\text { parts lifecycle }\end{array}$ & $\begin{array}{l}\text { Visibility intro supplier } \\
\text { performance }\end{array}$ & $\begin{array}{l}\text { Real-time delivery estimation and } \\
\text { stakeholder engagement }\end{array}$ \\
\hline $\begin{array}{l}\text { 1. Collect operations data in real-time } \\
\text { 2. Job tracking on the shop-floor } \\
\text { 3. Resource performance tracking } \\
\text { 4. Estimating and updating production } \\
\text { schedule after rush jobs }\end{array}$ & $\begin{array}{l}\text { Connected "things" - } \\
\text { parts, finished goods, } \\
\text { machines, }\end{array}$ & $\begin{array}{l}\text { Visual control for jobs and } \\
\text { resource performance tracking } \\
\text { in real-time }\end{array}$ & $\begin{array}{l}\text { Real-time resource allocation } \\
\text { ML for production control }\end{array}$ \\
\hline
\end{tabular}

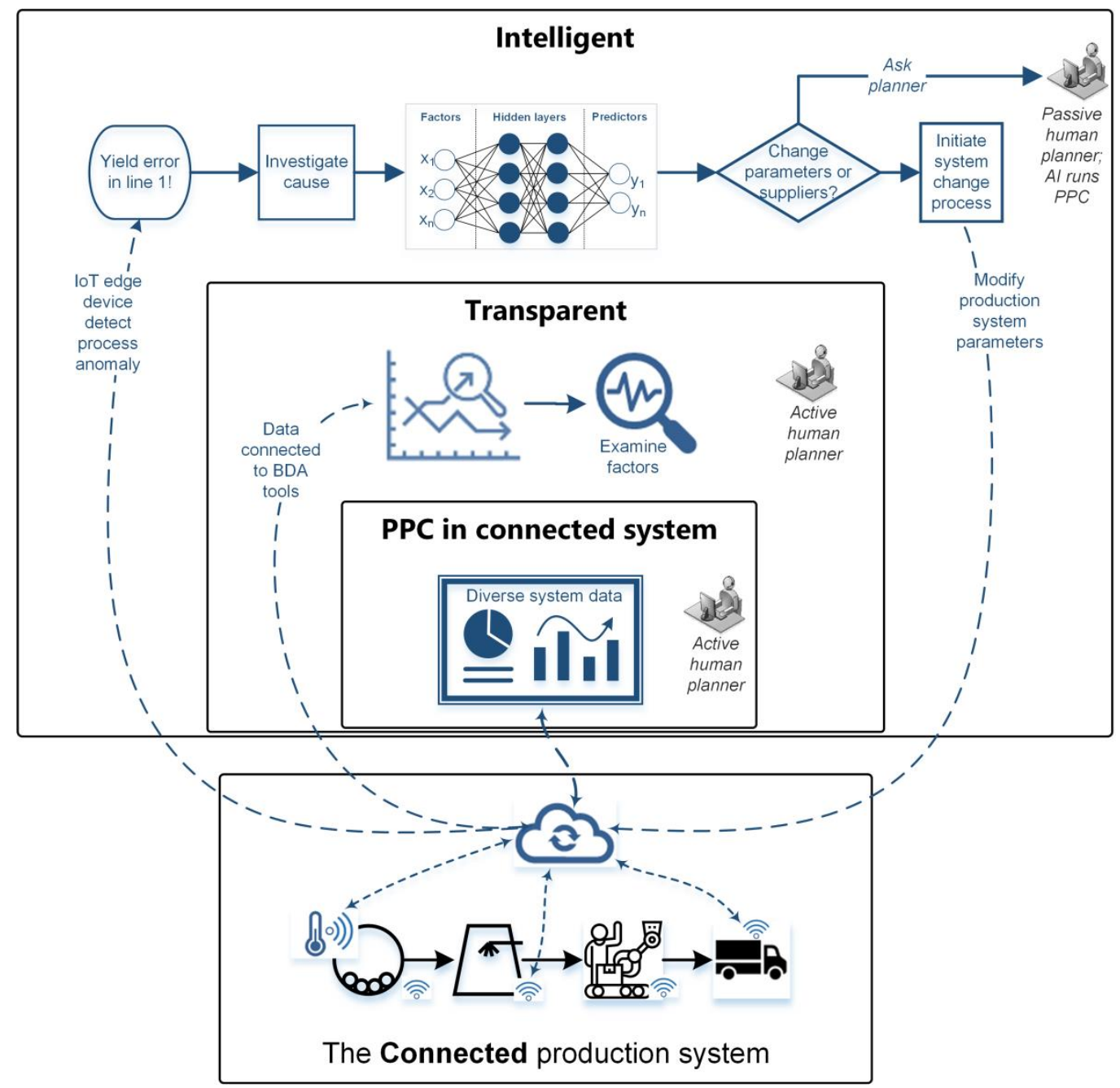

Figure 3. Conceptual model of smart PPC in a connected production system.

In general, smart PPC should perform better since it will be using a vast array of endogenous data from the production system and exogenous data from its environment. Moreover, for certain industries such as in process or semi-process production, there may be a greater opportunity to incorporate more data into the production planning and control processes.

\section{Case Studies}

In this section, we illustrate the theory with findings from case studies, by analysing current practices for PPC, digitalization and sustainability. For each case, we present a general overview and 
market factors, products, production process, PPC system and process, PPC challenges, digitalization initiatives and sustainability consideration in the current PPC processes at the case companies.

\subsection{Company A: Confectionery Products}

Market factors and general overview: Company A is a food company, manufacturing nuts, sweets (including pastilles) and chocolate from its single factory situated in Norway. In addition, the company also distributes fast-moving consumer goods for an international brand within Norway, leveraging its supply chain in the Norwegian market. The business encompasses all the value creation processes from product development, purchasing, logistics and production, to sales and marketing of mainly own brands. The company manages its product development, purchasing, production, supply chain logistics, sales and marketing along with its partners. Company A offers its products through the grocery industry, an industry valued at NOK 180 billion. In the business year 2018 and 2019, the company reported a turnover of NOK 750 million (USD 81 million). Many the sweets are impulsively purchased when customers are at the cashier stands in grocery stores. The level of competition is very high with economies-of-scale in product development being a key driver for market performance in the sweets market.

Products: Company A has a small R\&D department which is tasked with developing and testing new products. After a new product is approved, the supplier inputs are certified for quality, as the food industry is highly regulated due to potential safety risks to the consuming public. Currently, Company A has both the British Retail Consortium and the Det Norske Veritas (DNV) for its processes and supply chain. The company manufactures products under seven brand names. Under the confectionery section, Company A produces 19 product families.

Production process: Company A's factory is divided into three sections, one each for confectionery, chocolate, and nuts-based products. Due to regulatory requirements regarding the transference of allergens, the movement of people and materials across sections is controlled. Most critically, nuts-based products cannot be transported to the other sections producing products which will not be marked for potential nut-allergens. The production technology strategy for the future is to use flexible manufacturing systems - that is, machines that can process several products.

PPC system and process: Company A has a production planner role, responsible for making the final production schedule and monitoring its execution. Production plans are generated within the enterprise resource planning system. Company A currently uses Excel templates with formulas based on estimates of the relationships between planning variables. The planning process is heavily influenced by the promotions in Xmas, Easter, and other periods that are dictated by Company A's partners' marketing teams. Furthermore, production input materials are delicate and must be kept at narrow environmental limits; set-up time in the production process is high and finished goods and work-in-progress (WIP) inventory is also high; packaging lines are semi-independent, and product intermediates need to be transported to another section within the factory for packaging. In addition, schedules for each week are made at the end of the previous week based on firmed customer orders and MPS values; and the factory has a combination of processes with varying throughputs and levels of automation.

PPC challenges: The consequences of these challenges are as follows: highly seasonal, impulsive demand; queues/waiting and poor asset utilization due to poor material flow; high WIP inventory due to the combination of processes with varying throughputs and levels of automation; resource constraints and capacity limitations due to the fixed flow manufacturing processes; large swings in resource requirements due to the current heuristics-based planning approach. Furthermore, the bottleneck process (drying) limits the ability to increase plant throughput in its current form; production lead time is high due to high lot size and high set-up times; finished goods inventory is typically large due to the large number of products ( 51 from the confectionery business alone); high demand variation from promos; and problematic scheduling due to the multiple routes and large number of input materials. 
Current and planned digitalization initiatives contributing to smart PPC: Company A has implemented several automation projects in the past few years such as using robots in packaging and palletizing, using visual control and dashboards, etc. One such dashboard projects on the production lines provides direct access to data from the production line, thereby providing the planner real-time access into the status of the processes. The company is currently implementing a digital system which collects data from its production line and sends it to a data warehouse where BDA tools can be used to harness this data and generate meaningful insights. Despite these efforts, Company A struggles with its development of BDA and potential use of ML. While there may be several reasons for this, one of which is the complexity of the existing ERP system. The sheer cost of modifications and upgrades was highlighted as a major hinderance regarding the move to the use of smarter PPC through BI and big data analytics. However, new cloud solutions such as Microsoft Azure and Amazon Web Services offer a means to overcome such challenges.

Sustainability considerations in the PPC process: There are no explicit environmental sustainability considerations for the ongoing industry 4.0 initiatives. However, while the aims are purely economical, there is an implicit, unintended social benefit—-that is, to improve the decision-support tools for operators, thereby reducing stress. There is also an environmental benefit through waste reduction in the production system.

\subsection{Company B: Plastic Pipes and Custom Drainage Subsystems}

General overview and market factors: Company B is a large producer of plastic pipe systems and is a member of one of Europe's leading conglomerates in the market for plastic pipes and associated parts. Company B's piping systems have been used in water, sewage, cable protection, electrical installations and gas. The company has factories in Norway, and trading operations in Sweden, Norway, Finland and the Baltic States; it is a market leader in the supply of plastic pipe systems in that region of Europe. A considerable share of the production is exported, particularly large dimensioned polyethylene (PE) pipes for which Company B has developed a strong global brand reputation. However, the competition is stiff, final customers are SMEs and are often price sensitive.

Products: Company B manufactures and markets a wide range of quality pipe systems, providing tailor-made solutions for municipal infrastructure as well as for the industrial and house-building sectors. In addition, PE pipes, polyvinylchloride (PVC) pipes, and plastic-protected cables are produced to stock in a wide range of colours. There is also a section for customized solutions, mainly drainage solutions such as manholes and curved pipes with precise angular dimensions.

Production process: The main products, PE and PVC pipes, are produced using injection moulding and blow forming. The PVC pipes are produced in several similar production lines, and the processes are fully automated from feeding the raw materials into the mixing chamber and then dosing this mix into the moulding lines. For a few of the production lines, particularly those producing the smaller units, the packaging at the end of the lines is fully automated. In the customized goods department, a substantial amount of manual work is involved with the operators cutting, milling, grinding and welding high-strength section of large PE pipes.

PPC system and process: There is no production planner title at Company B, but the function of production planning is jointly managed by the production manager and the supply chain manager. The sections in the factory have different control principles, with the PE, PVC, and plastic-protected cables mostly produced to inventory (except for cases where property developers or municipality projects place a large order). The company also produces customized drainage solutions such as manholes and curved pipes.

PPC challenges: The challenges associated with PPC at Company B centre around tracking and tracing materials and components in the factory, inaccurate inventory levels in the input materials' warehouses, and suboptimal material flow in certain sections of the factory. Purchasing is based on inventory levels in the ERP system. There is the issue of inventory levels of input components (e.g., pipe covers) not matching what is on the ERP system. This is due to outdated product data and BOM data 
on the ERP system; failure by operators to update the materials register when materials are consumed; and losses during the movement of products from the factory to other locations. It also happens that drawn-down pallets are occasionally returned to the warehouse after a batch is produced, and where it is still counted as a full pallet, since the measurement system counts pallets and not a measure of the contents. The pallet count is only reduced when a full pallet is emptied. The storage location of items can occasionally be haphazard since the factory has several storage facilities within the factory complex and operators occasionally forget to move pallets of consumables to the designated locations.

Current and planned digitalization initiatives contributing to smart PPC: Company B is involved in projects to improve material flow within the factory and the production efficiency of the operation. At the operational level, these include a pilot project investigating the use of autonomous guided vehicles (AGVs), and an investigation and pilot of ML for an autonomous error detection and classification in the PVC production lines. The company has also investigated the use of RFID for material control in the shop floor and warehouses. In addition, Company B is also involved in a collaboration project for a digital platform solution for the industry which will enable closer interaction with the final customers and create new product configuration discoveries.

Sustainability considerations in the PPC process: Company B maintains an environmental account and tracks its carbon footprint. From the planning perspective, the production department operates a small recycling station which grinds waste or defective products which can then be reused in manufacturing new products. However, the planning processes aims to have an inventory of potential demand due to the competitive nature of the market and thus keep a large inventory which is not lean in that sense, but one that the company deems necessary to compete in its market.

\subsection{Company C: Equipment for Small and Large Ship Manufacturers}

General overview and market factors: Company $\mathrm{C}$ is a global supplier of heavy-duty propulsion, positioning and manoeuvring systems to shipping yards and marine companies with a turnover of 1000 million NOK (130 million USD) in 2014 and a workforce of just over 500 employees. The company, which has a subsidiary in Germany, manufactures thrusters which are used in manoeuvring large maritime vessels and smaller boats. Company $\mathrm{C}$ designs and produces all its products in-house to customer specifications, taking full responsibility for the delivered system. Only a few components are outsourced from nearby, tightly integrated suppliers.

Products: Company C offers electric, hybrid and diesel drive systems and provides service and support for the entire lifetime of the supplied system. In general, product complexity is relatively high; demand varies highly and is relatively low in comparison with, for example, an automobile engine manufacturing plant. Product variety is also high and typically require considerable engineering time and competence, due to the degree of customization accepted from customers. In addition, products have a very deep and wide product structure vis-à-vis the bill of materials (BOM). The company also manufactures a few small standardized thrusters.

Production process: Raw materials are purchased using estimates from order backlog received from suppliers and kept in inventory. The purchased raw materials (e.g., sheet metal) are taken to the machining department based on the material estimates from the manufacturing BOM in line with the production orders released to the shop floor. The welding and final assembly for most customer orders are difficult to plan due to the significant variation in the throughput time. For the complete product from order confirmation to delivery, the throughput time can be a few weeks for smaller, more common systems and months for the more complex products.

PPC system and process: Products are made to order. Due to the variability in the welding and final assembly processes, production planning is typically focused on machine availability planning. Currently, production planning is performed using a combination of simple Microsoft Excel spreadsheets and the ERP system Infor M3 enterprise management system. Although equipped with an untested finite capacity option, Company C, like several other companies in this industry, does not use this functionality. The reason in this case was the lack of experience with the functionality and the 
concern of the production planners that the plans could be disrupted and thus, lead to unpredictable consequences if used; therefore, the company uses the default setting, which the planning team is more comfortable with. A key company objective is to maximize output while maintaining the current cost levels- that is, to maximize throughput without increasing overtime cost or additional cost due to subcontracting.

PPC challenges: Complex, highly customizable production leads to variations in the production planning, so much so that planning then relies on shift planning with large planning buffers. In addition, material planning is order-driven and not forecast based due to the high holding cost of components and materials. Demand exhibits large variability due to the increasing chaotic global economy which affects customers, thereby making forecasting problematic. The consequence of all these and the current PPC system is that orders are consistently late by up to four weeks, which is why the planners always use a three-week buffer in the production plans.

Current and planned digitalization initiatives contributing to smart PPC: There is the smart welding project which aim to use robots to improve the quality, speed and cost performance of the welding process. There is also a plan to develop a rough-cut-capacity planning MS Excel tool for the planners and the sales team to be able to quickly check available-to-promise (ATP) capacity before confirming a new customer order. Finally, there is a new plasma and water cutting machine with an integrated software for managing the production process and inventory of steel plates.

Sustainability considerations in the PPC process: The company has sustainability goes which include improving the sustainability rate, reducing energy consumption, designing products to minimize environmental impact and identifying environmental contribution to the value chain. However, these are not explicitly measured in relation to the performance of the PPC processes.

\subsection{Company D: Agricultural and Industrial Balers}

General overview and market factors: From its headquarters in Norway, Company D began operations in 1949, manufacturing small, detachable tools for its local farming community. With its increasing innovation capacity, the company produced the world's first chopping baler with a coupled forage harvester in 1986. Further innovations in product development followed with the production of the integrated baler machine in 1987, and the world's first compactor in 2002. It has been found that there is an increase of up to $20 \%$ in milk production when cows consume forage stored in the form of bales compared to those consuming forage stored in silos. The effect of this improvement in agricultural milk production has led to increasing demand for bale production machines-a form of combine harvesters. In addition, the ease of transportation of bales compared to forage stored in silos spurred the demand for these products, which also includes demand in other industries, such as in the industrial waste management industry. This new application area is gaining increasing attention due to the improved ease of transportation and handling after compacting refuse into bales wrapped in plastic foil.

Products: Company D manufactures several variants of its novel baling machines, which are broadly classified into three product families. The first product family is the oldest, and the second and third product families have been developed in response to market needs. The third family of products has a variant used in waste management industry for baling refuse waste into smaller volumes and has lately experienced increasing demand. This variant also has higher strength properties to meet the needs of non-agricultural industries.

Production process: The production facility is organized in a functional layout. There are several workstations within the various departments, beginning from cutting, welding, painting, drying, and final assembly before shipment to customer. There are 10 welding stations and 15 assembly stations. Some of the welding is automated after several years of research and development.

PPC system and process: Company D uses an MRP system-Visma Business-for tracking the purchase and consumption of materials from inventory, but not for production planning. Production planning is done using a customized MS Excel template with formulas and prebuilt functions. Production control is done using another customized solution which is integrated into the material 
database within the MRP system. The production planner, who is also the plant manager, leads the planning meeting once every week where the sales and technical team leads the evaluation of new orders, and available capacities to meet the new production plan.

PPC challenges: Due to the level of customization and the complexity of the products produced by Company D, several challenges are being faced in the PPC process. For example, there is a substantial variation in the reported task completion times and a significant amount of aggregation in planning process, using averages and large buffers. Furthermore, the working time that operators record each day differs from the actual working time since it often happens that progress is updated in batches and not in real-time. Moreover, the Excel template used for production planning only considers the availability of resources in terms of total aggregated man-hours regardless of skill, but the template does not consider the differences-for example, even though there are 80 available hours in the electrical department and 20 available hours in the hydraulics department, the total of 100 hours might be misleading if 50 percent of the operations required for the day in question is hydraulics. This is a major issue since some of the assembly operations require specialist technicians.

Current and planned digitalization initiatives contributing to smart PPC: Company D ventured into the development of precision farming solutions in 2014 and is increasing the digital capability of its products to improve product lifecycle. There are also lean efforts, like kit-based planning to improve the assembly operation. In addition, there is an ongoing research project to develop and test a decision support tool for selecting geography-oriented marketing and a method for sharing plans and forecasts in Company D's value chain using new ICT technologies.

Sustainability considerations in the PPC process: Sustainability is not an explicitly considered element in the PPC process, even though the company has sustainability goals which are top priority for management, and which guide the overall operation of the business.

\section{Insights from the Literature and Case Studies}

Following the case description and analysis, in this section, we reflect on our findings from the cases by analysing the cross-case observations in Section 6.1. Thereafter, we discuss these findings within the backdrop of the literature presented earlier. The discussion is structured according to the two remaining research questions (RQs). Having addressed RQ1 in Section 4, we address RQ2 in Section 6.2 by discussing how extant enterprise planning systems, company and industry attributes, and supply chain structure enable or inhibit smart PPC as seen from the cases studies. Thereafter, we discuss the sustainability implications of smart PPC (RQ3) and attempt an explanation for why the case data revealed little explicit influence of sustainability KPIs on current PPC processes in the observed cases. We conclude this section with a brief discussion of a few managerial implications of these findings (Section 6.3).

\subsection{Cross-Case Summary}

A comparison of the case companies is presented in Table 3 below. While there are commonalities among the case companies, such as the trend of using simpler planning tools like spreadsheets, a common theme was the lack of KPIs for sustainability in the PPC planning process. Moreover, PPC challenges were more materials-related for the (semi-) process, make-to-stock (MTS) companies A and $\mathrm{B}$ and more capacity-related for the make-to-order (MTO) companies C and D. 
Table 3. Cross-case summary of planning environment attributes and industry 4.0 initiatives.

\begin{tabular}{|c|c|c|c|c|}
\hline & Company A & Company B & Company C & Company D \\
\hline Classification & Semiprocess; MTS $^{2}$ & Semiprocess; MTS & Discrete; $\mathrm{MTO}^{2}$ & Discrete; MTO \\
\hline Product and market & $\begin{array}{l}\text { Supplies nuts, sweets, and chocolate } \\
\text { products to few large retail chains }\end{array}$ & $\begin{array}{l}\text { Supplies plastic pipes to contractors } \\
\text { and wholesalers }\end{array}$ & $\begin{array}{l}\text { Supplies propulsion systems to } \\
\text { builders of ships and boats }\end{array}$ & Supplies large balers to final consumers \\
\hline Supply chain structure & $\begin{array}{l}\text { Customers (the wholesalers) current } \\
\text { have more power in SC }\end{array}$ & $\begin{array}{c}\text { Customers (the wholesalers) current } \\
\text { have more power in SC }\end{array}$ & $\begin{array}{l}\text { Dominant player in its SC; produces } \\
\text { most components in-house }\end{array}$ & $\begin{array}{l}\text { Small player in the lager agricultural equipment } \\
\text { and systems industry }\end{array}$ \\
\hline Planning tools & $\begin{array}{l}\text { Microsoft (MS) Excel for capacity and } \\
\text { enterprise resource planning (ERP) } \\
\text { for materials planning and control }\end{array}$ & ERP for all planning and control & $\begin{array}{l}\text { MS Excel (uses ERP system for } \\
\text { inventory control) }\end{array}$ & MS Excel (uses ERP system for inventory control) \\
\hline Key PPC challenges & $\begin{array}{l}\text { Large variations in plans vs. output; } \\
\text { poor visibility of operations }\end{array}$ & Material tracking; excessive inventory & $\begin{array}{l}\text { Available-to-promise capacity } \\
\text { difficult to estimate }\end{array}$ & $\begin{array}{l}\text { MRP inefficiencies in final assembly; large } \\
\text { CRP buffers }\end{array}$ \\
\hline Connected initiatives $^{1}$ & Operator dashboard access to planner & $\begin{array}{l}\text { Radio frequency identification (RFID) } \\
\text { for the connected factory }\end{array}$ & - & $\begin{array}{l}\text { Connected dashboard with the SFC systems; } \\
\text { connected product sending data to cloud }\end{array}$ \\
\hline Transparent initiatives $^{1}$ & $\begin{array}{l}\text { New dashboard for planning } \\
\text { and scheduling }\end{array}$ & Dashboard for production lines & $\mathrm{RCCP}^{2}$ tool to support sales process & Upgrade of planning tool for resource specificity \\
\hline Intelligent initiatives ${ }^{1}$ & ML for higher planning precision & ML for quality control in lines & - & $\begin{array}{l}\text { ML for processing product use data and predicting } \\
\text { service needs }\end{array}$ \\
\hline $\begin{array}{l}\text { Sustainability consideration in } \\
\text { PPC process }\end{array}$ & $\begin{array}{l}\text { Not considered explicitly, except at } \\
\text { the strategic level }\end{array}$ & $\begin{array}{c}\text { Yes, as a measure of the quantity sent } \\
\text { to recycling. }\end{array}$ & $\begin{array}{l}\text { Not considered explicitly, except at } \\
\text { the strategic level }\end{array}$ & $\begin{array}{l}\text { Not considered explicitly, except at the } \\
\text { strategic level }\end{array}$ \\
\hline
\end{tabular}

${ }^{1}$ Smart planning initiatives include both those that are recently deployed within the past three years or currently being developed or piloted. ${ }^{2}$ MTS = Make-to-stock; MTO = Make-to-order; $\mathrm{RCCP}=$ rough cut capacity planning . 


\subsection{Constraints and Enablers in Transitioning towards Smart PPC}

\subsubsection{The Influence of Extant Enterprise and Data Systems Influence Smart PPC}

In this paper, we examined PPC (a function that is ordinarily performed by ERP systems) and we presented a new system which uses existing tools and takes advantage of emerging smart technologies namely IoT, BDA and ML. Hence, this study could have also been carried out, perhaps, as an investigation of the extended capabilities of enterprise systems. Indeed, some authors consider ERP systems as the foundation for smart manufacturing operations [66] and we saw this same perspective in a few of the case companies.

Interestingly, these companies also appear to be averse to having their transition to smarter PPC tied to their ERP systems. For example, a manager at Company A complained about the company's need to upgrade to the latest version of the ERP system being used at the company. However, the same manager simultaneously raised concerns about the expensiveness of offers from IT vendors for the implementation of some of the upgrades that management desires to prepare the company for IoT, BDA and ML utilisation.

Furthermore, while the current ERP (and other enterprise) system(s) technology has led to better business processes and financial planning [30], its value as a complete production management solution remains limited in practice. One reason for this is the cost of the regular upgrades to latest versions with up-to-date functionalities. This is somewhat linked to the issue of customization and its implications for buggy integration with future upgrades and security updates of the core ERP system. The other reason is the complexity of most ERP installations which leads to numerous companies using their ERP systems for MPS and MPR but not for detailed day-to-day or shift-to-shift scheduling, a function now reserved for spreadsheets such as Microsoft Excel. Therefore, in order to have smarter production systems, managers investigating any or all the triad of smart PPC technologies go with the development of new cloud-based solutions which then connects to the ERP database through a data warehouse solution.

In addition, the form and quality of the data generated by extant enterprise systems are very important, and the ability to handle different formats can be a critical factor in determining success $[24,36]$. There are two types of data that production systems generate-stream and batch-and these data types require different types of processing in order to derive insights from them. While it would be expected that a company which has enhanced processes and updated, standardized enterprise solutions are more likely to have the foundation to advance faster into smart PPC, we could not find any evidence for that within the case companies. In fact, the company that was most keen on smart PPC was one which was using an older, nonagile ERP solution-that is, Company A.

However, both companies $\mathrm{A}$ and $\mathrm{B}$ had a significant amount of automation and process sensors which can easily be reconfigured and connected to the internet for a smart PPC solution. Using the stream data in the ERP and from the PLCs of the machines in the production line, Companies C and $\mathrm{D}$ instead pursued solutions that could enhance their capacity planning processes, which were their most critical PPC challenges (from their managements' perspective). In addition to extant data sources, Company A also sees potential in using exogenous data and historical data in improving the precision of its production planning process. However, the quality of historical data records which such a smart PPC system would need is in a form that cannot be used without arduous pre-processing. This data quality problem was more prevalent than anticipated and was also influential in determining the ease or difficulty of beginning or advancing towards smart PPC—consistent with Bean and Davenport [17].

\subsubsection{The Influence of Planning Environment Variables}

We also identified that process-based companies are more likely to benefit from (and therefore, should follow) a smart process strategy, with smart PPC as the driver. For MTO companies, we find that the path to smart control is towards smart products with simplified PPC processes that will continue to allow human control for the required process flexibility. In addition, previous studies have shown that 
certain industrial sectors such as steel, chemical and plastics and SMEs in general pursue industry 4.0 primarily for operational benefits, while large companies tend to seek long-term strategic benefits from industry 4.0 technologies [33]. As PPC processes contribute more towards operational performance, one would expect similar results. Furthermore, from the case studies, we see why this may be the case. Company $\mathrm{C}$, which is the largest of all four case companies, is a global market leader in its industry and the industry has a high barrier of entry where each product is typically very expensive and highly customized and the products are critical components of the ships they are installed on. In addition to a few projects to automate certain production processes like welding-a very difficult task to automate for MTO production-Company $\mathrm{C}$ has focused mostly on innovative technologies that enhance the products by increasing their digital content and making them "connected". The same holds true for Company D.

For Companies A and B, the products are standardized, have no digital element, are more difficult to digitize (even though pallets can be), and are more likely to be produced from raw materials which are chemically transformed in semi- or fully automated production lines. Therefore, the greater interest of Companies A and B in smart PPC is understandable because they are more inclined to pursue smart processes (and, consequently, smart PPC) rather than smart products, illustrated in Figure 4 below. This can be explained by the fact that these two environments have different kinds of PPC challenges and data generation processes. Process manufacturing tends to have more automated production lines that already generate data and little product complexity, which implies that process data is also consistent and repeatable, thereby enabling smart PPC. The same reason also enables more data granularity for analysis and in a format that is amenable to BDA and ML.

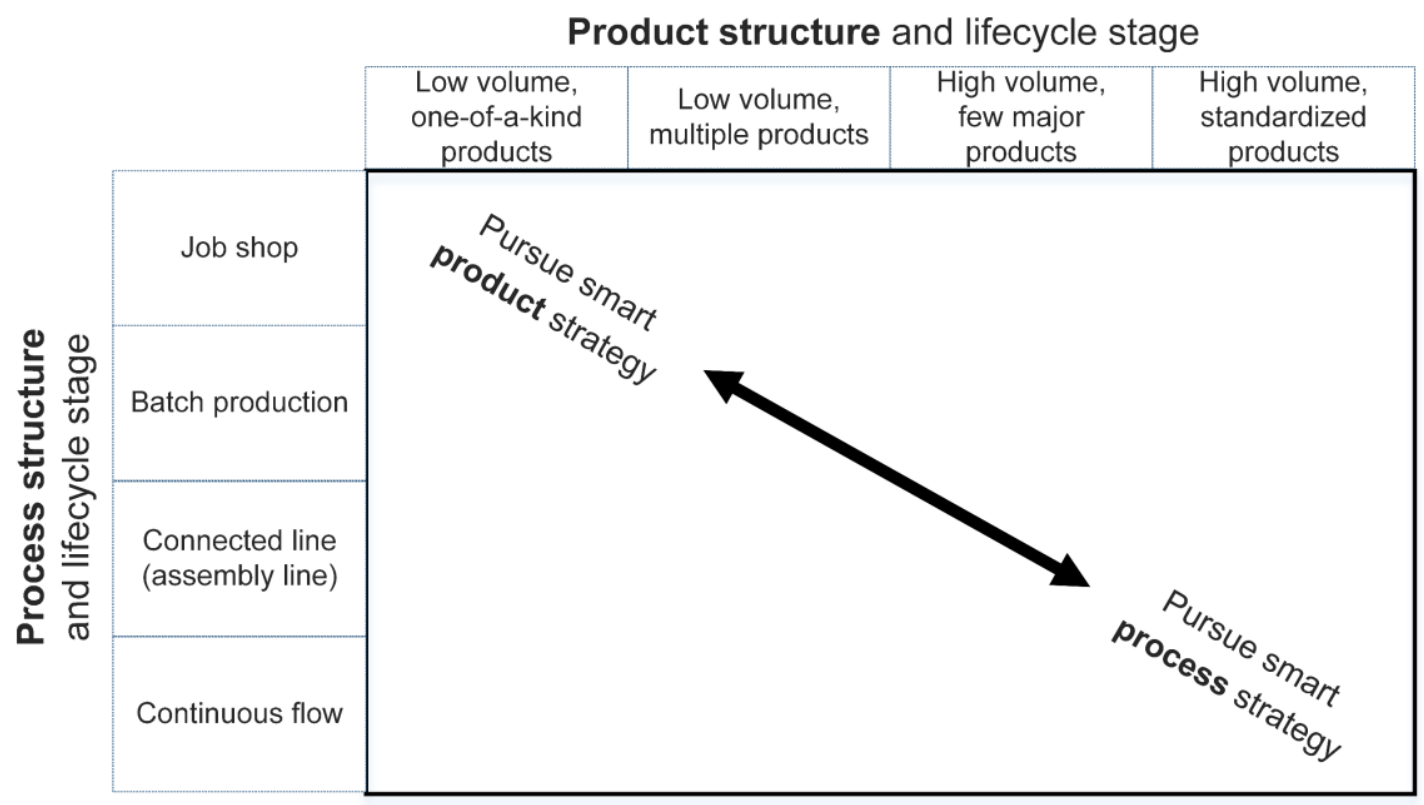

Figure 4. Product-process framework for smart PPC (Adapted from [67]).

In addition, process manufacturing, as seen in Companies A and B, is more amenable to exogeneous telemetry factors which can play a greater role in final production output, particularly when the production is not sufficiently isolated from its environment. Meanwhile, complex products producers with job shop layouts are more focused on balancing workloads and planning human operator requirements due to the high labour content. Furthermore, complex products manufacturers tend to have functional layouts and require much more manual or operator activity. This implies that complex products manufacturers are less likely to generate data in a consistent and repeatable format which, along with the high human content of the operation, makes it less amendable to process digitization. 
Hence, MTO operations tend to benefit more from process simplification, improved coordination, and a smart product strategy rather than from a smart process strategy.

Finally, we found evidence to support the observation by Veile et al. [16] regarding the success/failure of industry 4.0 projects in terms of horizontal integration. For example, Company C-which is more powerful relative to other members of its supply chain - tended to dictate the pace of industry 4.0 related innovation within its supply chain. Moreover, the intensely competitive industries tend to have more innovations activities. In this case, we found that Company $\mathrm{A}$, which has a relative small market share in a highly competitive food industry is more eager to pursue innovations that foster horizontal integration to the extent possible with its supply chain partners and has encouraged joint research projects with its major customers, which are mostly retail conglomerates.

\subsection{Sustainability and Managerial Implications}

Studies have shown (for example, in the automotive industry [33]) that anticipated operational and strategic gains are the primary drivers of industry 4.0 solutions, despite some of its core sustainability benefits. In this regard, our findings align with the results of previous studies as all the case companies in this study-except one (Company B) — had no any explicit sustainability measures or factors driving the PPC process, even though in all but one of the cases, planners were aware of the sustainability goals of their companies and their internal KPIs. The reasons for this are unclear, but it could be because of the following.

First, the level of societal consciousness regarding sustainability is rather high in Norway and it will be difficult to find a company which does not have "sustainability" somewhere in its mission, vision, or core value statements. Furthermore, all the companies in this study have had lean improvement programs at some point in the past decade and demonstrate all the visible elements of lean in their factories. Coupled with the high level of decision making permitted in Norwegian factories, it appears that the responsibility for sustainability has been given to operators on the shop floors in line with a bottoms-up approach. Although this has good benefits, it limits the true sustainability performance to only broad measures like carbon footprint, thereby missing the opportunity to have a truly robust sustainability strategy. Smart PPC will address this, for example, by explicitly enabling the integration of environmental and social KPIs with the financial. Smart PPC can enable sustainability KPIs to be included in the performance parameters of the system, thereby enabling these companies to actively and comprehensively act on their overarching sustainability goals. However, it will require new competences and training from operators and production planners and may also lead to stress and overextension, as observed by Birkel et al. [68].

Secondly, it has also been reported in the literature that managers will occasionally invest in a new fad (e.g., blockchain) or new technology (e.g., cloud computing, a critical enabler of data analytics and BI) due to the fear of missing out. A study of SMEs in Malaysia found that the likelihood that an SME adopts cloud computing increases when competitors are already using the same technology [69]. However, the key question is one regarding the fit of organizational structures, products and production processes, market and PPC processes, and how these issues can influence the use of any new technology in general and IoT, BDA and BI tools in smart PPC specifically. Ultimately, the greatest value is obtained when managers pursue the smart product or process direction that is fitting for their type of company.

In general, managers of companies producing complex, high variety low volume product are more likely to derive most value from pursuing a smart product strategy while those with standard, nonelectronic products in mass production environments are more likely to derive more value from a smart process strategy. In the latter case, a smart PPC solution has great potential and can drive an efficient, autonomous learning production system while tangibly addressing sustainability goals.

\section{Conclusions}

One important limitation of extant of research within industry 4.0, its technologies and their applicability, is the limited empirical content. In this paper, we attempted to bridge this gap by delving 
deep into the processes and operations of four case companies in four different types of industries and spanning both MTS and MTO production environments. In answering the need for a systematic, low-risk adoption of industry 4.0 and its technologies, this posed three guiding questions to guide out research for a solution, namely, to describe a smart PPC, the constraints and enablers of such a system and the sustainability implications for manufacturing. We proposed an incremental, conceptual model for development of the smart PPC system within manufacturing companies and exemplified this model with use-cases and the case studies.

\subsection{Contributions to Theory}

The theoretical contributions of this study to extant research are three-fold. First, the proposed conceptual model and matrix of use-cases can serve as a reference for production managers and other decision makers struggling in efforts to make their production systems more data-driven and intelligent. Moreover, while technologies such as data analytics and BI methods are not new in PPC research, the combination with IoT and the incremental implementation smart PPC approach reduces the risk and enables a natural maturation to smart manufacturing, both essential indicators for SMEs and companies with limited innovation R\&D budgets.

Secondly, we found that industry 4.0 implementations should not only integrate adequately with an organization's existing processes and systems, but also with its planning environment. In other words, the planning environment variables — product, production process, and market (i.e., supply and demand processes) - should dictate how industry 4.0 is approached, and consequently, each firm's implementation of smart PPC. Furthermore, the intensity of competition in a firm's industry can influence its need for, and adoption of, smart PPC solution. Companies in highly competitive industries, which are not market leaders are more likely to join the smart 'bandwagon' and in doing so, fail to achieve the fit that is necessary for implementation success.

Third, we have argued that even though the industry currently has no explicit sustainability KPIs guiding the PPC processes, this can be ameliorated in a smart PPC system. This last point is double-edged. On the one hand, we can build environmental KPIs into a smart PPC solution to reduce waste and other deleterious effects of manufacturing operations, while on the other hand, a mature smart PPC solution might lead to a reduction in the need for human planners where one planner could end up comfortably handling an operation hitherto managed by several planners.

\subsection{Limitations and Future Research}

Considering how limited the sample size for this study is, no bold claims can be made regarding the generalizability of its findings. We have explored the questions of interest through four case companies all based in Norway, albeit with varied company sizes, reach, market positions, and industry structures. Therefore, the location of these companies (being based in Norway) could have influenced our findings as opposed to, say, being situated in Germany which has a much diverse and extensive industrial economy or even neighbouring Sweden which has a larger industrial base. Furthermore, we also expect that the intensity of promotion of smart operations will be greater in industries which are of national strategic importance such as the oil and gas servicing industries in Norway or the automotive manufacturing industry in Germany. Therefore, our findings may be skewed in the sense that it may not reflect the current level of activity on the topic at a national level, for example.

In addition, the technologies in question are evolving and we have studied these case companies only for a short period of time, while the future development paths of these technologies (and vision of industry 4.0) are unknown. Moreover, this study did not capture the effect of popular improvement concepts like lean as factors in our case studies, even though there may be an association with industry 4.0 [70]. This was not without consideration though, as we observed that all four companies had mature lean programmes-with signs of visual control, 5S, and Kanban clearly visible in their factories. Furthermore, this study focused primarily on the perspective of the company and not the supply chain, although the influence of both the supply chain and, to a lesser extent, industry structure was 
considered as planning environment factors throughout the study. While this choice was fitting for this study as it allows for a nuanced investigation of the subjects, a focus on the supply chain might also yield interesting insights. Nevertheless, since the aim of this study was to explore a relatively young research area, we deem that the research design is adequate for the stated objectives based on the guidelines in Eisenhardt [71].

Future research could extend this study using a large sample size survey to further rigorously test if and to what extent the insights from this study are generalizable. A follow-up large scale national or international survey can address the limitations highlighted above. For example, while this study indicated that process and semi-process MTS producers are likely to favour a smart process strategy as compared to complex products MTO producers, future studies could also investigate what other factors-in addition to extensive process automation and the low or non-existent digital component of products-influence this choice and how these factors can be addressed by the producers of complex products. From the organizational perspective, the skills and capabilities of production planners and systems developers will be a critical success factor for achieving smart PPC, and studies that investigate the required skill sets and how to institutionalize that knowledge will be valuable insights for industry. Finally, with regard to the implementation of the smart PPC system, longitudinal studies that evaluate actual performance improvements achievable in practice when using a fully developed smart PPC system could reveal how much of an effect a smart PPC system can have on improving operational performance and sustainable manufacturing in the factories of the future.

Author Contributions: Conceptualization, O.E.O., F.S. and J.O.S.; methodology, O.E.O.; validation, O.E.O., F.S. and J.O.S.; formal analysis, O.E.O.; investigation, O.E.O.; resources, J.O.S.; data curation, O.E.O.; writing-original draft preparation, O.E.O.; writing-review and editing, O.E.O. and F.S.; supervision, F.S. and J.O.S.; project administration, J.O.S.; funding acquisition, J.O.S. Please turn to the CRediT taxonomy for the term explanation. All authors have read and agreed to the published version of the manuscript.

Funding: This research was funded by The Research Council of Norway, under the BIA project Manufacturing Network 4.0, number 247637.

Acknowledgments: The authors thank the companies in the completed Manufacturing Network 4.0 project and the ongoing DigiMat project for granting access to company employees for interviews, for factory visits, and for general insights about their respective industries. The authors also express gratitude to the anonymous reviewers for their recommendations and comments during the review process.

Conflicts of Interest: The authors declare no conflict of interest.

\section{Appendix A. - Interview Guide}

1. About the PPC environment variables: demand and supply characteristics, product attributes, and production system:

a. Describe the demand characteristics of your market

b. Describe the supply characteristics of your market

c. Describe your products' attributes in terms of

i. Bill of materials levels

ii. Level of digital/electronic functions;

iii. Shelf-life;

iv. Number of process routes (no. of production lines could be an indicator)

d. Describe your production system in terms of
i. layout;
ii. level of automation;
iii. level of product customization;
iv. intensity of operator input

2. PPC process and system: process, inputs, outputs, technologies, key stakeholders, current challenges 
a. Describe the planning process from beginning to the end, step-by-step.

b. Level of standardization:

i. To what extent is the planning process standardized? What decisions is a planner allowed to use his discretion for?

c. Highlight the following for the planning process:

i. Frequency of production planning meeting;

ii. General planning accuracy and how much planning buffer is usual;

iii. Planning horizon;

iv. Detailed scheduling horizon;

v. Frequency of rescheduling

d. PPC process data:

i. $\quad$ Describe the input and output data for every step of the planning process;

ii. What are the sources of these data and in what format is it?

iii. Are these data used for improvement of the planning process?

e. Describe (if any) the technology used for each step of the process (Excel, paper, SAP modules, etc.)

3. History of use of data-driven decision-making:

a. Data-driven methods in planning and controlling operations. This is with regards to not just having data from automated production lines, but do you use this data in planning and scheduling or is it used mostly for quality control?

b. Does your company use any of the following:

i. $\quad$ General business KPIs?

ii. KPIs for PPC process performance?

iii. Lean manufacturing elements: 5S, Visual control, SMED, Kanban, Heijunka, Just-in-time, etc.?

iv. Data-intensive improvement methodologies such as statistical process control, six-sigma, etc.

4. Digitalization approach and initiatives in general

a. Has your company completed any digitalization initiative/project in the last 3 years?

i. If yes, how many?

ii. Which technologies and which use-cases?

iii. What was the expected business or operations outcome?

iv. Which initiatives failed, and succeeded?

v. What challenges did you face during the implementation and use?

b. Is your company currently working on any digitalization initiative/project?

i. If yes, how many?

ii. Which technologies and which use-cases?

iii. What was the expected business or operations outcome?

iv. What challenges are you facing with the development, implementation and use?

c. Is your company planning any future (within the next 1-3 years) digitalization initiative/project?

i. If yes, how many? 
ii. Which technologies and which use-cases?

iii. What is the expected business or operations outcome?

5. Smart PPC decision making initiatives and the supply chain

a. In addition to the initiatives/projects mentioned above, are there any others that perhaps where smaller, but addressed or affected the PPC process directly or indirectly?

b. Has the company considered any initiative because other partners in the SC are developing that?

c. Or was is mandated by the SC partner(s)? If yes, rank this customer among several other customers?

6. What is your opinion on potential of smart technologies in improving the PPC process? (process, inputs, challenges eliminated)

a. Which elements of your planning process and system can be enhanced using smart technologies?

b. What do you think are possible limitations of having smart PPC?

7. How does this contribute to your sustainability goals?

a. Do you have specific sustainability goals for the year? If yes, what are they?

b. Do you currently have KPIs related to sustainability goals?

c. How do the company's sustainability goals affect your PPC processes and activities?

d. Do planners use sustainability parameters when driving the PPC process?

\section{References}

1. Bragdon, J.H.; Marlin, J. Is Pollution Profitable. Risk Manag. 1972, 19, 9-18.

2. Galpin, T.; Whitttington, J.L.; Bell, G. Is your sustainability strategy sustainable? Creating a culture of sustainability. Corp. Gov.: Int. J. Bus. Soc. 2015, 15, 1-17. [CrossRef]

3. Flint, D.J.; Golicic, S.L. Searching for competitive advantage through sustainability. Int. J. Phys. Distrib. Logist. Manag. 2009, 39, 841-860. [CrossRef]

4. Singhal, K. Sustainable Operations Management. Ssrn Electron. J. 2005, 14, 482-492. [CrossRef]

5. Wiendahl, H.-H.; Von Cieminski, G.; Wiendahl, H.-P. Stumbling blocks of PPC: Towards the holistic configuration of PPC systems. Prod. Plan. Control. 2005, 16, 634-651. [CrossRef]

6. Vollmann, T.E.; Berry, W.L.; Whybark, D.C.; Jacobs, F.R. Manufacturing Planning and Control for Supply Chain Management, 5th ed.; The Mcgraw-Hill/Irwin Series in Operations Decision Sciences; McGraw-Hill: New York, NY, USA, 2005.

7. Arnold, J.R.T.; Chapman, S.N.; Clive, L. Introduction to Materials Management, 7th ed.; Pearson Prentice Hall: Upper Saddle River, NJ, USA, 2012.

8. Ivanov, D.; Tsipoulanidis, A.; Schönberger, J. Digital Supply Chain, Smart Operations and Industry 4.0. In Universitext; Springer Science and Business Media LLC: Berlin, Germany, 2018; pp. 481-526.

9. Strandhagen, J.O.; Vallandingham, L.R.; Fragapane, G.; Strandhagen, J.W.; Stangeland, A.B.H.; Sharma, N. Logistics 4.0 and emerging sustainable business models. Adv. Manuf. 2017, 5, 359-369. [CrossRef]

10. Fatorachian, H.; Kazemi, H. Impact of Industry 4.0 on supply chain performance. Prod. Plan. Control. 2020, 1-19. [CrossRef]

11. Moeuf, A.; Pellerin, R.; Lamouri, S.; Tamayo, S.; Barbaray, R. The industrial management of SMEs in the era of Industry 4.0. Int. J. Prod. Res. 2017, 56, 1118-1136. [CrossRef]

12. Machado, C.G.; Winroth, M.P.; Da Silva, E.H.D.R. Sustainable manufacturing in Industry 4.0: An emerging research agenda. Int. J. Prod. Res. 2019, 58, 1462-1484. [CrossRef]

13. Sun, D.; Huang, R.; Chen, Y.; Wang, Y.; Zeng, J.; Yuan, M.; Pong, T.-C.; Qu, H. PlanningVis: A Visual Analytics Approach to Production Planning in Smart Factories. Ieee Trans. Vis. Comput. Graph. 2019, 26, 1. [CrossRef]

14. Ren, L.; Zhang, L.; Tao, F.; Zhao, C.; Chai, X.; Zhao, X. Cloud manufacturing: From concept to practice. Enterp. Inf. Syst. 2013, 9, 186-209. [CrossRef] 
15. Trunzer, E.; Calà, A.; Leitão, P.; Gepp, M.; Kinghorst, J.; Lüder, A.; Schauerte, H.; Reifferscheid, M.; Vogel-Heuser, B. System architectures for Industrie 4.0 applications. Prod. Eng. 2019, 13, 247-257. [CrossRef]

16. Veile, J.W.; Kiel, D.; Müller, J.M.; Voigt, K.-I. Lessons learned from Industry 4.0 implementation in the German manufacturing industry. J. Manuf. Technol. Manag. 2019. [CrossRef]

17. Bean, R.; Davenport, T.H. "Companies Are Failing in Their Efforts to Become Data-Driven." Harvard Business Review. Available online: https://hbr.org/2019/02/companies-are-failing-in-their-efforts-to-become-datadriven (accessed on 29 December 2019).

18. Leitão, P. Agent-based distributed manufacturing control: A state-of-the-art survey. Eng. Appl. Artif. Intell. 2009, 22, 979-991. [CrossRef]

19. Bonney, M. Reflections on production planning and control (PPC). Gestão Produção 2000, 7, 181-207. [CrossRef]

20. Garetti, M.; Taisch, M. Neural networks in production planning and control. Prod. Plan. Control. 1999, 10, 324-339. [CrossRef]

21. Sánchez-Herrera, S.; Montoya-Torres, J.R.; Solano-Charris, E.L. Flow shop scheduling problem with position-dependent processing times. Comput. Oper. Res. 2019, 111, 325-345. [CrossRef]

22. Oluyisola, O.E.; Strandhagen, J.W.; Buer, S.-V. RFId technology in the manufacture of customized drainage and piping systems: A case study. Ifac-Pap. 2018, 51, 364-369. [CrossRef]

23. Oluyisola, O.E.; Salmi, T.E.; Strandhagen, J.O. Causes of Delivery-Time Variance in Maritime-Equipment Manufacturing Supply-Chains: An Empirical Study. In Proceedings of the Nonlinear Model Predictive Control; Springer Science and Business Media LLC: Berlin, Germany, 2018; pp. 415-421.

24. Gustavsson, M.; Wänström, C. Assessing information quality in manufacturing planning and control processes. Int. J. Qual. Reliab. Manag. 2009, 26, 325-340. [CrossRef]

25. Schuh, G.; Potente, T.; Hauptvogel, A. Methodology for the Evaluation of Forecast Reliability of Production Planning Systems. Procedia Cirp 2014, 17, 469-474. [CrossRef]

26. Stock, T.; Seliger, G. Opportunities of Sustainable Manufacturing in Industry 4.0. Procedia Cirp 2016, 40, 536-541. [CrossRef]

27. Stock, T.; Obenaus, M.; Kunz, S.; Kohl, H. Industry 4.0 as enabler for a sustainable development: A qualitative assessment of its ecological and social potential. Process. Saf. Environ. Prot. 2018, 118, 254-267. [CrossRef]

28. Hermann, M.; Pentek, T.; Otto, B. Design Principles for Industrie 4.0 Scenarios. In Proceedings of the 201649 th Hawaii International Conference on System Sciences (HICSS); Institute of Electrical and Electronics Engineers (IEEE): Piscataway, NJ, USA, 2016; pp. 3928-3937.

29. Iansiti, M.; Lakhani, K.R. Digital Ubiquity: How Connections, Sensors, and Data Are Revolutionizing Business. Harv. Bus. Rev. 2014, 92, 19.

30. Reynolds, G. Information Technology for Managers; Nelson Education: Toronto, ON, Canada, 2015.

31. Dubey, R.; Gunasekaran, A.; Childe, S.J.; Papadopoulos, T.; Luo, Z.; Wamba, S.F.; Roubaud, D. Can big data and predictive analytics improve social and environmental sustainability? Technol. Soc. Chang. 2019, 144, 534-545. [CrossRef]

32. Dalenogare, L.S.; Benitez, G.; Ayala, N.F.; Frank, A.G. The expected contribution of Industry 4.0 technologies for industrial performance. Int. J. Prod. Econ. 2018, 204, 383-394. [CrossRef]

33. Müller, J.M.; Kiel, D.; Voigt, K.-I. What Drives the Implementation of Industry 4.0? The Role of Opportunities and Challenges in the Context of Sustainability. Sustainability 2018, 10, 247. [CrossRef]

34. Schuh, G.; Anderl, R.; Gausemeier, J.; ten Hompel, M.; Wahlster, W. "Industrie 4.0 Maturity Index." Managing the Digital Transformation of Companies; Herbert Utz Verlag: Munich, Germany, 2017.

35. Banker, R.D.; Bardhan, I.R.; Lin, H.C. Plant Information Systems, Manufacturing Capabilities, and Plant Performance. Mis Q. 2006, 30, 315. [CrossRef]

36. Wamba, S.F.; Akter, S.; Edwards, A.; Chopin, G.; Gnanzou, D. How 'big data' can make big impact: Findings from a systematic review and a longitudinal case study. Int. J. Prod. Econ. 2015, 165, 234-246. [CrossRef]

37. Ngai, E.W.; Law, C.; Wat, F. Examining the critical success factors in the adoption of enterprise resource planning. Comput. Ind. 2008, 59, 548-564. [CrossRef]

38. Koh, L.; Gunasekaran, A.; Goodman, T. Drivers, barriers and critical success factors for ERPII implementation in supply chains: A critical analysis. J. Strat. Inf. Syst. 2011, 20, 385-402. [CrossRef]

39. Jabbour, A.B.L.D.S.; Jabbour, C.J.C.; Foropon, C.; Filho, M.G. When titans meet-Can industry 4.0 revolutionise the environmentally-sustainable manufacturing wave? The role of critical success factors. Technol. Soc. Chang. 2018, 132, 18-25. [CrossRef] 
40. Sousa, R.; Voss, C.A.; Voss, C. Contingency research in operations management practices. J. Oper. Manag. 2008, 26, 697-713. [CrossRef]

41. Hicks, C.; McGovern, T.; Earl, C.F. A Typology of UK Engineer-to-Order Companies. Int. J. Logist. Res. Appl. 2001, 4, 43-56. [CrossRef]

42. Høyer, M.R.; Oluyisola, O.E.; Strandhagen, J.O.; Semini, M.G. Exploring the challenges with applying tracking and tracing technology in the dairy industry. Ifac-Pap. 2019, 52, 1727-1732. [CrossRef]

43. Meredith, J. Building operations management theory through case and field research. J. Oper. Manag. 1998, 16, 441-454. [CrossRef]

44. Handfield, R.B.; A Melnyk, S. The scientific theory-building process: A primer using the case of TQM. J. Oper. Manag. 1998, 16, 321-339. [CrossRef]

45. Jonsson, P.; Mattsson, S.-A. The implications of fit between planning environments and manufacturing planning and control methods. Int. J. Oper. Prod. Manag. 2003, 23, 872-900. [CrossRef]

46. Wilhelm, M.; Blome, C.; Wieck, E.; Xiao, C.Y. Implementing sustainability in multi-tier supply chains: Strategies and contingencies in managing sub-suppliers. Int. J. Prod. Econ. 2016, 182, 196-212. [CrossRef]

47. Yin, R.K. Case Study Research: Design and Methods, 4th ed.; Sage Publications: Thousand Oaks, CA, USA, 2009.

48. Klaus, H.; Rosemann, M.; Gable, G. What is ERP? Inf. Syst. Front. 2000, 2, 141-162. [CrossRef]

49. De Man, J.C.; Strandhagen, J.O. Spreadsheet Application still dominates Enterprise Resource Planning and Advanced Planning Systems. Ifac-Pap. 2018, 51, 1224-1229. [CrossRef]

50. Liao, Y.; Deschamps, F.; Loures, E.D.F.R.; Ramos, L.F.P. Past, present and future of Industry 4.0 - a systematic literature review and research agenda proposal. Int. J. Prod. Res. 2017, 8, 1-21. [CrossRef]

51. Davies, J. Understanding IPv6, 3rd ed.; Microsoft Press: Seattle, WA, USA, 2012.

52. Chen, B.; Wan, J.; Celesti, A.; Li, D.; Abbas, H.; Zhang, Q. Edge Computing in Iot-Based Manufacturing. IEEE Commun. Mag. 2018, 56, 103-109. [CrossRef]

53. Kärkkäinen, M. Increasing efficiency in the supply chain for short shelf life goods using RFID tagging. Int. J. Retail. Distrib. Manag. 2003, 31, 529-536. [CrossRef]

54. Ustundag, A.; Tanyas, M. The Impacts of Rfid Technology on Supply Chain Costs. Transp. Res. E Logist. Transp. Rev. 2009, 45, 29-38. [CrossRef]

55. Huang, B.; Wang, W.; Ren, S.; Zhong, R.Y.; Jiang, J. A proactive task dispatching method based on future bottleneck prediction for the smart factory. Int. J. Comput. Integr. Manuf. 2019, 32, 278-293. [CrossRef]

56. Park, K.T.; Nam, Y.W.; Lee, H.S.; Im, S.J.; Noh, S.D.; Son, J.Y.; Kim, H. Design and implementation of a digital twin application for a connected micro smart factory. Int. J. Comput. Integr. Manuf. 2019, 32, 596-614. [CrossRef]

57. Kritzinger, W.; Karner, M.; Traar, G.; Henjes, J.; Sihn, W. Digital Twin in manufacturing: A categorical literature review and classification. Ifac-Pap. 2018, 51, 1016-1022. [CrossRef]

58. Kuo, Y.-H.; Kusiak, A. From data to big data in production research: The past and future trends. Int. J. Prod. Res. 2018, 57, 4828-4853. [CrossRef]

59. Kusiak, A. Artificial Intelligence and Operations Research In Flexible Manufacturing Systems. Infor: Inf. Syst. Oper. Res. 1987, 25, 2-12. [CrossRef]

60. Brintrup, A.; Pak, J.; Ratiney, D.; Pearce, T.; Wichmann, P.; Woodall, P.; McFarlane, D. Supply chain data analytics for predicting supplier disruptions: A case study in complex asset manufacturing. Int. J. Prod. Res. 2019, 1-12. [CrossRef]

61. Monostori, L.; Markus, A.; Van Brussel, H.; Westkämpfer, E. Machine Learning Approaches to Manufacturing. Cirp Ann. 1996, 45, 675-712. [CrossRef]

62. Shiue, Y.-R.; Lee, K.-C.; Su, C.-T. Real-time scheduling for a smart factory using a reinforcement learning approach. Comput. Ind. Eng. 2018, 125, 604-614. [CrossRef]

63. Corsten, H.; May', C. Artificial neural networks for supporting production planning and control. Technovation 1996, 16, 67-93. [CrossRef]

64. Hruschka, H. Determining market response functions by neural network modeling: A comparison to econometric techniques. Eur. J. Oper. Res. 1993, 66, 27-35. [CrossRef]

65. Wróblewska, A.; Stanisławek, T.; Prus-Zajączkowski, B.; Garncarek, Ł. Robotic Process Automation of Unstructured Data with Machine Learning. Position Pap. 2018 Fed. Conf. Comput. Sci. Inf. Syst. 2018, 16, 9-16. [CrossRef] 
66. Haddara, M.; Elragal, A. The Readiness of ERP Systems for the Factory of the Future. Procedia Comput. Sci. 2015, 64, 721-728. [CrossRef]

67. Hayes, R.H.; Wheelwright, S.C. Link Manufacturing Process and Product Life Cycles. Harv. Bus. Rev. 1979, 57, 133-140.

68. Birkel, H.; Veile, J.W.; Müller, J.M.; Hartmann, E.; Voigt, K.-I. Development of a Risk Framework for Industry 4.0 in the Context of Sustainability for Established Manufacturers. Sustain. 2019, 11, 384. [CrossRef]

69. Hassan, H. Factors Influencing Cloud Computing Adoption in Small and Medium Enterprises. J Inf. Commun. Technol. 2020, 16, 21-41.

70. Buer, S.-V.; Strandhagen, J.O.; Chan, F.T. The link between Industry 4.0 and lean manufacturing: Mapping current research and establishing a research agenda. Int. J. Prod. Res. 2018, 56, 2924-2940. [CrossRef]

71. Eisenhardt, K.M. Building Theories from Case Study Research. Acad. Manag. Rev. 1989, 14, 532. [CrossRef]

(C) 2020 by the authors. Licensee MDPI, Basel, Switzerland. This article is an open access article distributed under the terms and conditions of the Creative Commons Attribution (CC BY) license (http://creativecommons.org/licenses/by/4.0/). 